\title{
A Scoping Study of Water Table Excursions Induced by Seismic and Volcanic Events
}

Charles R. Carrigan

Geoffrey C.P. King

George E. Barr

November 1990

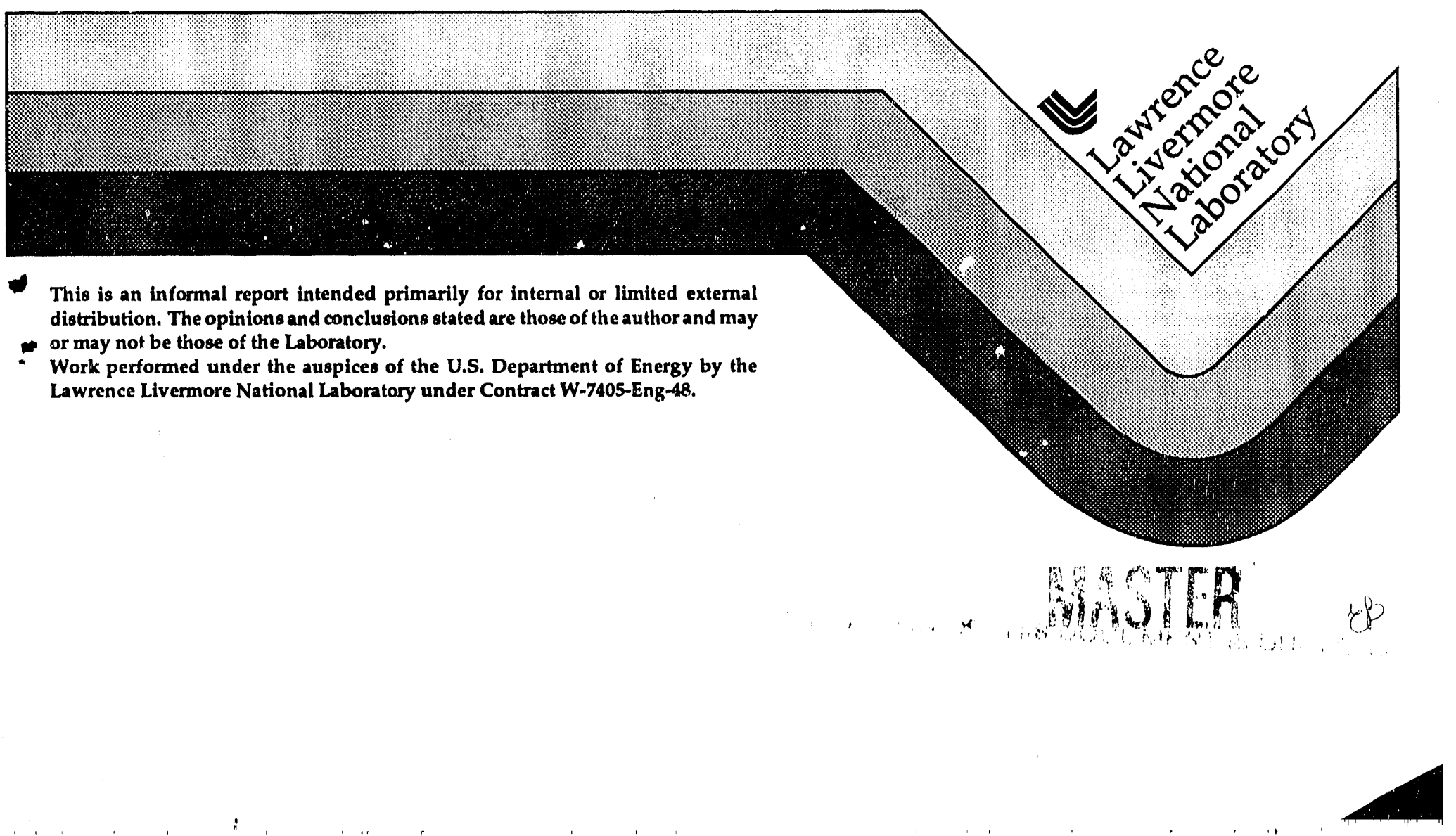




\section{DISCLAIMER}

This document was prepared as an acccount of work sponsored by an agency of the United States Government. Neither the United States Government nor the University of California nor any of their employees, makes any warranty, express or implied, or assumes any legal liability or responsibility for the accuracy, completeness, or usefulness of any information, apparatus, product, or process disclosed, or represents that its use would not infringe privately own rights. Reference herein to any specific commercial products, process, or service by trade name, trademark, manufacturer, or otherwise, does not necessarily constitute or imply its endorsement, recommendation, or favoring by the United States Government or the University of California. The views and opinions of authors expressed herein do not necessarily state or reflect those of the United States Government or the University of California, and shall not be used for advertising or product endorsement purposes.

This report has been reproduced directly from the best available copy.

Available to DOE and DOE contractors from the Office of Scientific and Technical Information P.O. Box 62, Oak Ridge, TN 37831

Prices available from (615) 576-8401, FTS 626-8401

Available to the public from the National Technical Information Service

U.S. Department of Commerce 5285 Port Royal Rd., Springfield, VA 22161 
A Scoping Study of Water Table Excursions

Induced by Seismic and Volcanic Events

\author{
Charles R. Carrigan \\ Lawrence Livermore National Laboratory \\ Geoffrey C.P. King \\ University of Strasbourg \\ George E. Barr \\ Sandia National Laboratories
}

\begin{abstract}
We develop conservative models of water table response to displacements just beneath the water table simulating (1) shallow intrusion of a dike and (2) high level slip on a normal fault locked at the end. For matrix flow, we find local water table excursions of unc'er $10 \mathrm{~m}$. in cases of isotropic permeability which includes dike inflation of $4 \mathrm{~m}$ and fault slips corresponding to earthquakes having a moment magnitude of 7.4. Even for enhancements of vertical permeability up to $104: 1$, excursions did not exceed $15 \mathrm{~m}$ which implies that pumping is strongly volume limited. We also present an analysis of upward directed flow in cracks for the case of earthquake induced pore pressure changes. For matrix properties characteristic of the Calico Hills (vitric) formation and a crack distribution bounding the potential flow capacity of published data, we estimate an upper bound of $0.25 \mathrm{cu} \mathrm{m}$. of ground water per $\mathrm{m}$. of fault length as the amount capable of being pumped to a level $250 \mathrm{~m}$. above the normal water table. While the presence of even larger fractures than assumed might carry more ground water to that level, an absolute upper limit of less than $50 \mathrm{cu}$. $\mathrm{m}$. per $\mathrm{m}$. of fault length is available to be pumped assuming a value $n=0.46$ for the rock porosity. For less porous rocks typical of the Topopah Springs or Tiva Canyon formations $(n \approx 0.10)$ the upper limit may be reduced to less than $10 \mathrm{cu} . \mathrm{m}$. per $\mathrm{m}$. of fault length. This upper limit depends only upon strain, the height of pumping above the water table and the formation porosity.
\end{abstract}




\section{Introduction}

We report the results of a scoping study to investigate processes leading to water table excursions at Yucca Mountain. The motivation for this study arises from the recognition of a dearth of quantifiable models to either defend (Szymanski, review draft 1987; $1989)$ or criticize the thesis of large, temporal changes in the water table level at the proposed site for a high level nuclear waste repository. The DOE sponsored review (Dudley et al., 1989) of the Szymanski manuscript echoes this view in stating that a need exists for "calculations with simplified phenomenological models [to] establish the magnitudes of both potentiometric and water table response to physically possible ranges of stress changes".

During the past 3 years of dialogue on the suitability of Yucca Mtn as a possible site for a waste repository, various mechanisms have been proposed, usually in a qualitative manner, as having the potential to cause substantial changes in the water table level. These basic ideas and their variants seem to fall into one of three groups having to do with climatic changes, tectonism and volcanism. No attempt is made to evaluate all these concepts. Rather, we have decided to focus on the often mentioned mechanical coupling between elastic and hydrologic processes that may be considered to be characteristic of both tectonic and volcanic events. The model of Sibson et al. (1975), which introduces the concept of "seismic pumping", is prototypical of those tectono/volcano-hydrologic processes that we investigate here. Initially, we attempt to quantify the implications for water table excursions of the specific example given by Sibson et al. (1975). Much of the latter part of this 
report will be devoted to developing coupled elastic/hydrologic models using existing computer programs to quantify various aspects of a generalized mechanism that couples deformation, produced either by fault slip or magmatic intrusion, to water table excursions.

It is emphasized that the elastic and hydrologic models developed in the course of this scoping effort approximate what we believe are realistic situations in terms of the stress and hydrologic regimes. Whenever it has been necessary to employ simplifying assumptions, we have attempted to select ones that enhance water table response. Thus, we view our models as providing upper bounds on excursions of the saturated zone for precisely the cases represented.

\section{Background}

The effects of seismicity and volcanism might affect the water table through two different categories of processes. The passive category represents those hydrologic models in which a ground water flow is modified by spatially non-uniform hydraulic conductivity resulting from faulting or intrusive volcanism. The Garlock fault-zone northeast of Los Angeles appears to provide an excellent example of the structural control of a hydrologic system (Lippincott et al., 1985). Two wells separated in a transverse direction in the fault-zone by about 1 kilometer have exhibited virtually independent behavior regarding changes in water table levels. The presence of a branch of the fault between the two wells presumably results in a region of low hydraulic conductivity. 
Similarly, a volcanic dike complex has been linked to the formation of a hydraulic gradient at Kilauea Volcano in Hawaii (Jackson and Kauahikaua, 1987). Estimates of the depth to the water table based upon self-potential methods indicate that ground water may be retained at abnormally high elevations (100-200 $\mathrm{m}$ above sea level) within the east rift zone. A hydraulic gradient in the vicinity of Yucca Mtn. may be an example of this kind of control (Barr and Miller; 1987, Czarnecki and Wadell, 1984).

The movement of the water table by production of a pore/fracture pressure change resulting from seismicity or volcanism characterizes the active category of processes. The dilatancy-diffusion seismic mechanism (Frank; 1965, Nur; 1972) motivated the qualitative : vork of Sibson et al. (1975) upon which some of the concern about water table rise at Yucca Mountain is based. The pattern of mineralization observed to fill fractures in trench 14 at Yucca Mtn. does bear some similarity to that described by Sibson et al. (1975) as being an indicator of the operation of a cyclic seismic pumping mechanism. In the model of Sibson et al., the intermittant pattern of mineral layering in veins is explained by the gradual reopening of old mineralized fractures followed by the strain induced flow of solutions such as carbon dioxide saturated brines that, according to their theory, follows seismic events. Successive cycles of reopening, fluid flow and plugging by mineralization result in veining with multiple layers.

That fault creep events can drive water level changes in wells is accepted to the extent that monitoring wells are viewed as strainmeters for tectonic activity (Johnson et al. 1974). Motivated 
by the diagnostic potential of wells for aseismic processes, a number of models have been developed for the response of water wells in confined aquifers near faults that are subject to translating creep events. In an aquifer covered by an impermeable cap, pore prossure changes caused by creep events translate into transient head changes in wells. In this circumstance, the well becomes a gauge for monitoring slip induced pressure changes in the aquifer. Using an analytical approach, Wesson (1981) found that water level changes in wells near the surface could be as much as several meters in response to a one meter dislocation propagating horizontally at the rate of $10 \mathrm{~km} /$ day along a strike-slip fault $10 \mathrm{~km}$ below the surface. His approximate model, which did not take into account diffusion or the effects of the capillary transition zone, related calculations of temporal pore pressure changes at a point to water well response with the aid of a "leaky integrator" model developed by Johnson et al. (1973).

In their model for strike-slip creep in the Garlock fault zone, Lippincott et al. (1985) performed similar calculations to model well response to a passing dislocation. They used the hydrostatic relationship between pore pressure change and head change, appropriate for the confined aquifer case, to obtain the response of the water table in wells. Again, their model did not treat pore water diffusion and the existence of a capillary transition zone. Their observations of water level changes of $15-30 \mathrm{~cm}$ are in response to creep events with amplitudes of several millimeters to one centimeter according to their models. 
For the confined aquifer model, the coupling of pore pressure changes that result from traveling dislocations to pore water diffusion was found to produce different well responses from those predicted by the above analyses (Roeloffs and Rudnicki, 1984j. More recently, this model has been used to investigate water well responses in a confined aquifer to a static distribution of strain resulting from a dislocation (Rudnicki and Hsu, 1988). The model was used to investigate the effect of a fault zone that acts as a barrier to hydrologic flow. Their results for the Garlock fault zone differ in detail from the earlier work of Lippincott et al. but tiley still indicate about the same amplitude of response for a given slip. All the models discussed involve observations made in wells at depth following a slip event. Because they all assume the special case of a well penetrating a confined aquifer, the calculated water level excursions are extreme. An estimate of the excursion of the "free surface" of the water table will be more useful for the problems considered here.

A number of anomalies associated with surface hydrology have also been reported in association with earthquakes. A recent compilation of reported hydrologic effects of selected North American earthquakes (Raney, 1988) chronicles the occurrence of surface effects such as water spouts and streams with large chariges in flow rate. Such observations have been occasionally used to infer very large pore pressure changes leading to large changes in the water table at depth. The new regional elastic/hydrologic models presented here support the view that short term surface events are highly localized in nature and result from near surface 
changes in strain that act upon water at or very near the surface. Indeed, all the elastic models presented here exhibit potential hydrologic source/sink regions of dilatation and compression at the surface that occur in conjunction with inflation of cracks or slip on faults at depths $0.75 \mathrm{~km}$ or more below. On this basis, we argue that short term changes in surface hydrology, such as sand boils, flow rate changes in streams and water spouts, are a poor indicator of the hydrologic state at depth.

\section{The Seismic Pumping Model of Sibson et al. (1975)}

The qualitative model of Sibson et al. (1975) was intended to explain observations of mineral veining. This model of tectonohydrologic coupling assumes the formation of a fractured dilatant zone that centers on $a$ fault and is a result of increasing crustal stresses. The occurrence of dilatancy is accompanied by a local decrease in pore pressure. In response to this decrease, ground water gradually diffuses into the dilatant region and into fractures with time which allows the pore pressure to rise again to its initial value. Finally, when rapid slip on the fault takes place, elastic forces attempt to return the zone to its original state of stress. However, the fractured rock mass is now filled with groundwater which begins to flow in response to these restoring forces. Since the model assumes a preferential vertical orientation for fractures, ground water is ejected vertically from the dilatant zone. It is assumed that this mineral rich ground water leaving the dilatant zone gives rise to precipitation in open cracks until plugging occurs. These cracks then cease to be a path for further hydrologic flow 
until a new round of stress building occurs that further widens them thereby reopening old paths for future pulses of ground water.

In the development of the model by Sibson et al., the formation of a dilatant region by fracturing of the rock mass is treated only in a kinematic sense with no reference to the dynamics of fracture formation in a system where confining stresses due to the lithostat are important. In fact, it still remains to be demonstrated that shear stresses on a strike-slip fault can even produce the hypothesized dilatancy distribution. The consensus among seismologists is that the evidence for dilatancy based upon observations of uplift and/or seismic velocity variations is meager to nonexistent. In addition, recent laboratory studies seem to suggest that the typical volumetric strains $\left(\Delta V / V=10^{-5}\right)$ assumed for an $m=6$ event in the model of Sibson et al. are small compared to volumetric strains associated with the growth of microcrack shear zones needed to produce significant new fracturing. By subjecting Indiana limestone to differential compressive stresses, it was found that unconfined samples required volumetric strains of order $10^{-3}$ before the coalescence of microcracks produced shear failure by fracture formation (Zheng, 1989). For confined samples, which simulate the effect of the lithostat, a transition from elastic to plastic deformation was typically observed beyond volumetric strains of approximately $3 \times 10^{-3}$ to almost $10^{-2}$, that is, failure due to large fracture formation usually did not occur. The results obtained by Zheng agree with the prevailing view that an increase in confining pressure makes the probability of microcrack interaction less likely (Kranz, 1983). Thus, in addition to a lack of new fracture 
formation at the values of dilatancy anticipated for the model of Sibson et al., Zheng's work also suggests that any new volume resulting from microcracking under confinement will be poorly interconnected. From a hydrologic perspective, this suggests that ground water flow from newly opened cracks in the dilatant zone will be limited by flow through the rock matrix.

The periodic opening and closing of existing water filled joints in response to earthquake induced changes in crustal stress is a mechanism that may warrant further consideration. While joints may have the potential to act as deformable reservoirs/pathways for ground water, several potential barriers to this mode of operation seem to exist. As opening of a joint occurs, propping is to be expected as mineralization or filling with debris occurs. This will limit the amount of closure that can occur after a slip event. In addition, a mineralized joint or one filled with fines may be less permeable than the surrounding rock matrix. Furthermore, for a highly jointed region, it is uncertain as to how much stress is available to drive closure of the joints following an earthquake since the presence of joints reduces the elastic restoring forces in the dilatant zone itself (see Engelder, 1987). The elastic crust exterior to the jointed zone will exert a normal stress of only several bars on the zone of dilatancy for a volumetric strain of $10^{-5}$. This estimate was obtained from the solution for the normal stress on the wall of an inflated void in an elastic medium (Roark, 1943).

For dilatancy to occur in the earth's crust, local tension must overcome not only elastic forces in the rock mass but also the contribution owing to the lithostat. Presuming that local tensional 
stresses are somehow adequate to do this, the question arises as to how long local stresses can act to either widen a crack or even keep it open in the presence of confining stresses. If the time scale over which relaxation of intense local stresses that give rise to individual fractures is short compared to the time over which regional aseismic stresses build (1-100 years), then fracture induced dilatancy will not occur. The tendency for local stress fields to relax or diffuse might be a result of such processes as crack tip propagation, creep and stress corrosion (Atkinson and Meredith 1987). Evaluation of the pertinent time scales for stress growth and relaxation processes remains as an important exercise to determine the applicability of dilation as the driving mechanism for seismic pumping.

From purely hydrodynamic considerations, it is readily arguable that seismic pumping is not required at all to move fluid through reopened fractures below the water table. After fractures are opened below the water table, ground water flow and chemical transport can be driven by temperature differences (thermal convection), mineral precipitation (double diffusive convection) and exsolution of phases (two-phase flow'). In this kind of model for mineralization, changes in the crustal stress field only serve to open or reopen fractures; the flow that occurs once the fracture is opened is driven by ubiquitous buoyancy forces that are always available to move fluid. A strong case can be made that the intermittancy of the veining patterns requires that some flow process occurred. However, the conclusion of Sibson et al. that 
seismic pumping is responsible for the flow is an extrapolation beyond the available observations.

Implication of the Model of Sibson et al. for Water Table Rise

In the paper by Sibson et al., no attempt is made to estimate the potential for the rise of the water table in response to an earthquake event of magnitude $m=6$. With the aid of several assumptions, it is possible to estimate the rise that might occur given the value of vulumetric strain used in their paper. The ten kilometer diameter dilatant region that they assumed for this $m=6$ event implies a total dilatant volume of 523 cubic kilometers. Using their assumed average volumetric strain of $10^{-5}$, we calculate an excess of $5 \times 10^{9}$ liters $\left(5 \times 10^{6} \mathrm{~m}^{3}\right)$ of water that would be available to raise the water table. We now make the exceedingly conservative and unrealistic assumption that all the excess water is somehow channeled from this large dilatant volume into a narrow $(100 \mathrm{~m}$ wide) fault zone of high permeability running the $10 \mathrm{~km}$ length of the dilatant region (Figure 1). Based upon the excess volume, we would anticipate a maximum rise of $50 \mathrm{~m}$ within the fault zone for a porosity of 0.10 .

Numerical Models for Water Table Response

The models presented here differ significantly, as enumerated, from previous quantitative models of tectono-hydrologic coupling. (1) The models treat the more general case of the "free surface" response of the water table in an unconfined aquifer. (2.) The existence of a vadose zone or capillary transition zone that avoids 
an unrealistic sharp transition from totally saturated to totally dry pore space is also taken into account. This feature results in greater excursions of the water table than would be predicted by models without this zone. (3.) The models for pore fluid flow include both over-pressuring due to compression and desaturation due to dilatancy below the water table surface, i.e., sources and sinks. The maximum pore pressures achieved in the models are comparable to those maxima pertaining to known slip events estimated by Raleigh et al. (1972). (4.) Anisotropic permeabilities favoring vertical water transport are employed in certain calculations. (5.) Hydraulic conductivity is realistically treated as a function of pressure head by combining van Genuchten's (1978) model for saturation and Maulem's (1976) model for hydraulic conductivity in all calculations. (6.) The boundary element elastic model for faults and dike intrusions includes the realistic free surface boundary condition.

\section{The Elastic/Hiv'rologic Solution}

A flow chart (Figure 2) is used to illustrate the method for obtaining water table excursions from displacements simulating intrusion of a dike or slip on a normal fault. The geometry and displacements assumed were input into a boundary element solver to obtain the volumetric strain distribution. To determine pore pressures from the volumetric strain, one of two poroelastic models were used. The resulting pore pressure field along with additional information about the hydrologic domain, physical properties and boundary conditions constitutes an initial value problem. A 
hydrologic code was used to solve this by tracking both the gradual relaxation of the initial pore pressure field and the response of the water table as water flowed away from zones of higher pressure. We now discuss details of this approach.

The program used to obtain the strain distributions used to determine pore pressure is based on boundary element methods described by Crouch and Starfield (1983). The version of the technique adopted approximates solutions to elastic problems using dislocation elements for which displacements are specified. The program can accommodate up to 1000 elements and media of differing elastic constants or gravitating media can be introduced. Facilities are available to set-up a wide range of boundary geometries and conditions and calculations can be carried out directly under half-space boundary conditions. Some of these applications are described by Bilham and King 1989, Hackman et al, 1990, King and Ellis 1990, King and Sammis 1990 and King et al., 1991. The technique for evaluating the stress/strain distribution of tectonic or volcanic features consists of introducing a series of dislocation elements into an elastic medium. The location and amplitude of slip or displacement on the elements, which represents the features dynamically, is then adjusted such that stresses and displacements at boundaries and interfaces reasonably approximate the real problem being examined. In the simple cases considered here, displacements have been assigned to single boundary elements positioned vertically below the surface of the half-space to simulate either inflation of a dike (displacement normal to the boundary element) or slip on a normal fault locked at its end 
(displacement along the boundary element). For each problem, the volumetric strain distribution was determined for the coordinates of each node on a grid of 4800 or 7200 nodes corresponding to that used in the finite element hydrologic solver.

Pore pressures were calculated as a function of the volumetric strain, $\Delta \backslash Y^{\prime} V=e_{x x}+e_{y y}$, according to ane of two models. One model assumed that in a compressed volume of rock, all the volume change would occur in the pore space, the rock matrix itself being incompressible. (For a non-welded tuff such as the vitric Calico Hills formation having a porosity of $n=46 \%$, a total volume decrease of $0.1 \%$ would imply a corresponding decrease in porosity of $0.1 / 46$ or $0.22 \%$.) The pertinent equation for the pore pressure change due to compression of pore space only is

$$
\Delta P=\frac{-M b}{n} \cdot(\Delta V / V)
$$

where $M_{b}$ is the bulk modulus for water. In terms of the diagonal strain components this expression yields

$$
\Delta P=-4.87 \times 10^{9} \cdot\left(e_{x x}+e_{y y}\right) n t / m^{2}
$$

The other model for the relationship between pore pressure and the strain field was obtained by equating pore pressure to the negative of the mean normal stress (Wesson, 1981), i.e., $P=-\frac{1}{3}\left(\sigma_{x x}+\sigma_{y y}+\sigma_{z z}\right.$ ).

In the most general form of the preceeding equation, a constant varying between zero and one, called Skempton's coefficient, should multiply the right side (see Rudnicki and Hsu, 1988). To be conservative in this analysis, we have set this constant equal to one. 
To determine the values of $\sigma \| l$ in our model, we used a plane strain formulation to find the stresses from the strains induced in the elastic half-space. The plain strain formulation requires that all strains lie in the $x-y$ plane with the $z$ component constrained to be zero. This formulation ensures maximal mean stresses. The mean of the three stress components (Crouch and Starfield, 1983) that result may be written as

$$
P=\frac{-E}{3}\left[\frac{1}{1-2 v}\right]\left(e_{x x}+e_{y y}\right)
$$

in which $E$ and $v$ are Young's modulus and Poisson's ratio for the rock matrix. For the Calico Hills vitric formation, the change in pore pressure is then

$$
\Delta P=-7.98 \times 10^{9} \cdot\left(e_{x x}+e_{y y}\right) n t / m^{2} .
$$

Because equation (3) results in a greater increase in pore pressure than equation (1) for the formation considered, we have used it for most of the calculations although the difference is not great enough to affect the implications of this analysis. It should also be noted that in some cases characterized by either a somewhat smaller value of porosity, $n$, or Young's modulus, $E$, equation (1) may produce a larger pore pressure change. However, this would imply that Skempton's coefficient can exceed unity. For the case in which a change in normal stresses in the rock matrix are themselves responsible for the pore pressure change, it is difficult to understand how this can happen. 
After conversion of the nodal values of volumetric strain to pore pressures, the nodal data was used in the hydrologic model as the initial values of the pore pressure field. The finite element code NORIA (Bixler, 1984) was used to solve the initial value problem for the response of the water table. Features of the code include the use of quadratic basis functions and eight-node rectangular elements. The problem solved is inherently transient and its solution utilized a time integration scheme which uses a predictorcorrector method coupled to a Newton iteration procedure. A major advantage of this particular integrator is automatic time step adjustment. Because the automatic procedure adjusts each time step to maintain a uniform time truncation error, even when natural time scales change severely, there was no need to estimate these time scales before beginning integration. For the problems discussed here, the natural time scales were found to vary from fractions of a second to years. Spatial resolution was guaranteed by using a biased mesh with finer spacing in the region where rapid changes in flow properties, such as saturation, or in the pressure field might occur. Mesh biasing at the water table permitted spatial resolutions on the order of one centimeter to be obtained. With biasing on both sides of the water table, it was found that, for the intrusion domain of $1 \times 2.1 \mathrm{~km}, 600$ elements were adequate to spatially resolve the water table response. For the normal fault case, 900 elements covering a $1.25 \times 1 \mathrm{~km}$ area were used. The hydrologic domain included between 50 and 100 meters of the unsaturated zone overlying the water table. This was found to be quite adequate since the water table rise never exceeded 15 meters 
above its initial level. The boundary conditions for the domain were no-flow horizontal and top boundaries and either a no-flow or constant pressure bottom boundary. Switching the bottom boundary conditions had no significant effect on the water table rise. The main advantage of the constant pressure bottom boundary condition is that water can flow in or out of the domain simulating more realistic far field behavior. In any case, the effect of a finite domain that covers the zcne of maximum pore pressures is to over estimate the actual water table rise.

Simulation of the capillary transition zone above the water table (defined here to be a saturation of $S=0.99$ ) is another of the major features of the hydrologic models presented here. In the hydrologic code, the saturation, $S$, or degree of pore filling is a nonlinear function of the pressure head, $\psi$, as modeled in the relationship of van Genuchten (1978),

$$
S(\psi)=\left(1-S_{r}\right)\left[\frac{1}{1+|\alpha \psi|^{\beta}}\right]^{\lambda}+S_{r}
$$

in which $\lambda=1-1 / \beta$.

The value of the saturation is also known to affect the hydraulic conductivity. For the unsaturated zone, we use van Genuchten's formulation given in equation (4) to express the hydraulic conductivity versus saturation model of Maulem (1976) in terms of pressure head:

$$
K(\psi)=K_{S}\left(1+|\alpha \psi|^{\beta}\right)^{-\lambda / 2}\left[1-\left(\frac{|\alpha \psi|^{\beta}}{1+|\alpha \psi|^{\beta}}\right)^{\lambda}\right]^{2} .
$$


The quantities $\alpha, \beta$ and $\lambda$ are empirically determined for each permeable material. They are given along with other physical properties for the Calico Hills (vitric) formation in Table 1. Our criterion in selecting properties for the hydrologic model was to bound the excess volume of water available to leave a compressed zone. The Calico Hills (vitric) formation is the highest porosity Yucca Mtn. layer and in this model the excess pore fluid is proportional to porosity. It is also characterized by relatively high matrix hydraulic conductivity which shortens transient response of the water table. The relative sparsity of fractures in this formation ensures that its composite hydraulic conductivity, which includes fracture flow, is about the same as its matrix conductivity (Klavetter and Peters, 1986). Use of a lower matrix conductivity will mainly affect the water table response time and not the amplitude of response.

\section{Case 1: Intrusion of a Volcanic Dike}

Dikes produced during the most recent episodes of volcanism near Yucca Mtn. are typically $2 \mathrm{~m}$ or less in width (Bruce Crowe, personal communication). There is also some evidence that a width of about $2 \mathrm{~m}$ represents an upper bound on the amount of inflation that rising magma can produce in the crust (Davis, 1983). This bound is based upon observations of surface tilt and the depth to seismic hypocenter locations produced by magma intrusion. For dikes that do not break the earth's surface, the model of Davis suggests maximum dike aspect ratios falling between $2-3 \times 10^{-4}$. The maximum depth of earthquakes in the basin and range province is 
roughly 10-15 km (G. Zandt, personal communication). Using this range as being characteristic of the maximum dike length for brittle regions of the crust, we would anticipate maximum dike widths produced soley by inflation to be about $2-4 \mathrm{~m}$. It is important to recognize that this calculation does not bound the total width of a dike. Rather, it bounds the contribution of widening produced by normal stresses that give rise to elastic strains in the surrounding wall rock. It is this mechanism for widening that will affect pore fluid pressures. The other mechanism for widening involves wall rock removal which should not significantly affect the stress field in the wall rock.

Figure 3 illustrates the contoured regions of dilatancy (black to gray) and compression (white to gray) resulting from the inflation of a $2 \mathrm{~m}$ dike that is assumed to end $750 \mathrm{~m}$ below the earth's surface and $250 \mathrm{~m}$ below the water table. (The placement of the water table, located $500 \mathrm{~m}$ below the surface, corresponds to its approximate depth at Yucca Mtn.) The dark frame represents the boundary of the finite element grid for the hydrologic solver. For all calculations the positioning of the domain always captured the regions of highest pore pressure. Profiles of the non-hydrostatic contribution to pore pressure at $1 \mathrm{~km}$ below the surface are shown in Figure 4 for 2 and $4 \mathrm{~m}$ dikes.

Figure 5 is a plot of water table surface at different times versus the horizontal coordinate for the $2 \mathrm{~m}$ dike. The upwelling is quite broad over the $1 \mathrm{~km}$ cross section with a weak peak at the center over the dike. At the peak, the maximum excursion for matrix flow is just under 4 meters ( $6 \mathrm{~m}$ for the $4 \mathrm{~m}$ dike). For $\mathrm{CHv}$ 
properties, the maximum value occurred $7.47 \times 10^{5} \mathrm{sec}$ (8.6 days) following the intrusion. The effect of anisotropy in the permeability or hydraulic conductivity is illustrated in Figure 6. Assuming a vertical permeability that was everywhere 10 times greater than the horizontal value which was set to the value of the isotropic $\mathrm{CHv}$ case, we found a more pronounced peak of about $6.5 \mathrm{~m}$ that occurred in less than one day $\left(6.1 \times 10^{4} \mathrm{~s}\right)$. In another simulation, we assumed anisotropy only in a $100 \mathrm{~m}$ wide strip centered on the dike. In this case, shown in Figure 7, we wanted to examine the focussing effect of a local vertical permeability enhancement of from $10^{1}$ to $10^{4}$ that might result from cracking induced by the intrusion (the isotropic case is included for comparison). Sharp peaks were produced by the vertical permeability enhancement. The maximum increased with each increase in the magnitude of the vertical permeability up to $10^{3}: 1$. Beyond $10^{3}: 1$ the peak went no higher, topping out at $12 \mathrm{~m}$, which suggests that any further rise was limited by the volume of ground water available to be channeled into the zone of enhanced permeability. The results for the $4 \mathrm{~m}$ dike with a zone of enhanced permeability are quite similar (Figure 8). Increases in vertical permeability resulted in increasing water table maxima up to a height of about $14 \mathrm{~m}$ which was achieved in the 103:1 case. While our models are for flow in an anisotropic matrix, we believe that the parallel with fracture flow is suffient to anticipate that ground water rise in fractures may also suffer from volumetric limitations.

The distribution of saturation as a function of height above the water table is another way to examine the effect of seismic 
pumping on ground water flow in the matrix. Figure 9 is a plot of the degree of pore saturation centered on the maximum excursion of the water table for the isotropic permeability case. The differences between the curves corresponding to the initial saturation distribution (squares) and the distribution at the maximum excursion of the water table (dlamonds) are rather small and occur only within $20 \mathrm{~m}$ of the initial water table level. A strip of high vertical permeability (10:1) centered on the dike does little to enhance the differences between the two curves as is apparent from Figure 10.

\section{Case2: Slip on a Normal Fault Locked at One End}

A survey of the region around Yucca Mtn. indicates the existence of numerous faults; the majority of which have either normal or normal/oblique offsets (URS/Blume and Associates, 1986). A maximum magnitude of 6.5 was estimated for earthquakes on these faults using the rupture dimension as a basis. We consider that a prototypical fault for the Yucca Mtn. region might be characterized by a normal slip of up to one meter corresponding to a moment magnitude of approximately 6.8-7.4. In order to enhance hydrologic effects, we assume that displacement occurs uniformly on the fault up to its end which is locked. Most of the volumetric strain then occurs in a fairly local zone. In addition, this lock point and its associated regions of large volumetric strain are assumed to be very shallow, occurring just beneath the water table.

Figure 11. illustrates the volumetric strain distribution for this case. The locked end of the fault lies $750 \mathrm{~m}$ below the surface 
and $250 \mathrm{~m}$ below the water table. The zones which grade from black to gray and white to gray represent zones of dilatation and compression respectively. As in Figure 3 , the black frame is the domain for the hydrologic problem. It is positioned to maximize the influence of the zone of compression on the water table response. Figures 12 and 13 are profiles of the volumetric strain taken across the fault at the water table level and just above the lock point 240 $\mathrm{m}$ below the water table level. The maximum values of volumetric strain are weakly dependent on the Poisson's ratio as shown in Figure 12. To facilitate comparison with the model of Sibson et al., we note that the volumetric strains near the fault in our model are up to two orders of magnitude larger than the characteristic value of $10^{-5}$ given by Sibson et al. On the other hand, our dilatant region is found to be much smaller (about $1 \mathrm{~km}$ across) than the $10 \mathrm{~km}$ figure used in their model.

Time dependent water table responses to slips of $0.10,0.25$, 0.50 and 1.0 meters are plotted in Figures 14-17 assuming isotropic permeability. In all cases the water table rises less than $6 \mathrm{~m}$. as indicated by the linear relationship between maximum water table excursion and slip plotted in Figure 18. Assuming properties appropriate to the Calico Hills vitric layer, it was found that the water table excursion reached its maximum within two days after the sllp event.

Using the moment magnitude relationship of Hanks and Kanamori (see Rundle, 1989), we can estimate the magnitude of an earthquake that might be associated with the slip amplitudes assumed here. In the relationship, 


$$
1.5 \mathrm{~m}=\log _{10} \mathrm{M}_{0}-16.1,
$$

$m$ and $M_{0}$ are respectively the earthquake magnitude and the seismic moment. The seismic moment is defined to be $M_{0}=\mu_{s} \varepsilon S$ where $\mu_{s}$ is the shear modulus, $\varepsilon$ is the fault slip and $S$ is the fault area. We eliminate the fault area using an expression for the stress drop, $\Delta \sigma$, which is a function of both fault area and slip, thus obtaining:

$$
m=0.67 \log _{10}\left[\frac{5.02 \mu_{s}^{3} \varepsilon^{3}}{\Delta \sigma^{2}}\right]-10.79
$$

The stress drop is a parameter that does not seem to vary strongly from one earthquake to another. A representative value of 10 bars is used in our calculations (Brune, 1968). Translation of slip into earthquake magnitude then yields the result of Figure 19. We find that our model would predict maximum water table excursions of 2 to $5.5 \mathrm{~m}$ for earthquakes with magnitudes ranging from 5.4 to 7.4 which bounds the largest events predicted for the Yucca Mtn. region.

The effect of enhancing the vertical permeability everywhere in the hydrologic domain is shown in Figure 20 for the $1 \mathrm{~m}$ slip case. As in the anisotropic dike model we find that large anisotropies do not have a major effect on raising the water table. An increase of $10^{3}$ times in the vertical permeability produces a maximum between 9 and $10 \mathrm{~m}$ that is approximately twice the the isotropic case. Increasing the ratio of vertical to horizontal permeability further results in very little if any increase in water table height. Water table response for a locally anisotropic regime (Figure 21), modeled by a strip of enhanced vertical permeability (up to $10^{3}: 1$ ) centered 
on the fault, falled to produce greater maxima than the regionally anisotropic case of Figure 20. In part, this is because little channeling of ground water into the zone of high anisotropy occurs during the rapid rise of this part of the water table near the fault. In addition, a strong sink for ground water is immediately adjacent to the pore pressure maximum in the anisotropic zone which should decrease the amplitude of excursion.

\section{A Model for Water Transported by a Fracture Network}

To this point, we have only considered flow in the permeable rock matrix. Fractures also represent a possible pathway for the transport of ground water above the water table. During transport of ground water, fractures have the advantage of minimizing pore water diffusion which is characteristic of transport in the rock matrix. In situations where only a limited amount of water is available for transport, fractures would seem to offer a more effective means for transporting it. This, however, assumes the idealization that no significant amount of the water being carried by a fracture is imbibed into the rock matrix. Recent modeling of fracture flow in the Topopah Springs unit (Buscheck and Nitao, 1988) and the vitric Calico Hills unit (Buscheck, personal communication) suggests that imbibition of water being transported in fractures is likely to have a major effect on decreasing upper bounds that are calculated here assuming no imbibition.

We consider the effect of coupling ground water storage in the matrix with transport in fractures. This is an arrangement that would seem to optimize the potential for seismic pumping since a 
large volume of fluid in the matrix becomes available to be transported along low diffusivity pathways to higher levels. The object of our calculation using a simple model is to bound how much water might be transported to levels that are $250 \mathrm{~m}$ or more above the water table. A pressure of at least 25 bars is required to support a column of groundwater in a sufficiently long vertical fracture that reaches this level (capillary rise in the fracture is negligible for the aperture considered). Thus only regions of pore space that are pressurized to more than 25 bars above the hydrostatic value can supply ground water to an elevation $250 \mathrm{~m}$ or more above the water table.

For the $1 \mathrm{~m}$ slip case $(m=7.4)$, we plot the transient pressure contour that contains the region of pore pressures greater than 25 bars (Figure 22). Pressure histories are plotted in Figure 23 for points corresponding to the highest initial pressure (235 bars) as well as near the most long lived part of this region which gradually vanishes as pore fluid diffuses through the rock matrix. If this zone is assumed to be permeated with fractures oriented vertically, flow into and along the fractures will occur. That flow will continue until the pressure field surrounding a fracture falls below the 25 bar threshold. Alternatively stated, the zone of high pressure decays and fractures at a given location will eventually fall outside the zone and no longer contribute to production of flow at the $250 \mathrm{~m}$ level. For these calculations, we select fracture apertures of 27 microns corresponding to the largest fractures commonly observed in core samples (Klavetter and Peters, 1986). We further assume a three fold density enhancement of three such fractures per $\mathrm{m}^{3}$ which 
are all oriented vertically. While fractures are often filled with sand, fault gouge or have asperities, we will treat them as ideal channels in our bounding model. The equation for the mass of water passing through the aperture, $a$, of a crack per unit time per unit horizontal length is

$$
\mathrm{Q}=\frac{1}{12} \frac{\Delta{\mathrm{P} \rho \mathrm{a}^{3}}^{3}}{\mu \mathrm{l}}
$$

where $\Delta \mathrm{P}$ is the pressure drop along the vertical length, $I$, of the crack. The pressure driving flow in the cracks is the mean of the elementally averaged pressures encountered by columns of vertical cracks in the zone of high pressure. As time progresses, the average pressure around a column of fractures discays. When the average falls below 25 bars, flow in the column ceases to contribute water at the $250 \mathrm{~m}$ level. As indicated in Figures 22 and 23, the high pressure zone vanishes in less than a day. During this time water could be pumped to the $250 \mathrm{~m}$ level according to our simple model. The spatial distribution of water supplied to this level is shown in Figure 24. The maximum flow would occur roughly $100 \mathrm{~m}$ from the fault plane. The total volume pumped to this level before the zone disappeared would be about $0.25 \mathrm{cu} . \mathrm{m}$. per $\mathrm{m}$. of fault length (Figure 25). Because the flow through a fracture depends on the cube of the aperture (Eq. 8), the volume pumped is extremely sensitive to the crack size. For example, 100 micron fractures have a flow rate for a given pressure drop of about 50 times that of 27 micron fractures. A total volume of $12 \mathrm{cu}$. m. per $\mathrm{m}$. of fault length would be estimated as the total volume pumped according to this model. A $0.001 \mathrm{~m}$ 
fracture filled with sand and asperities having an effective permeability of 100 darcies $\left(10^{-10} \mathrm{~m}^{2}\right)$ is approximately equivalent to an ideal 100 micron fracture in terms of the flow transported for a given pressure drop. (In making these kinds of estimates we assume that the resistance to flow in the rock matrix which feeds the crack is small compared to the resistance to flow along the crack. As crack aperture increases, this assumption becomes weaker. The resulting volume estimates become progressively "looser" upper bounds.)

There is an absolute limit on the amount of fluid that can be pumped from the zone of high pressure. For the $1 \mathrm{~m}$ slip case, the volume decreases from about $50 \mathrm{cu}$. $\mathrm{m}$ per $\mathrm{m}$. of fault length to zero as the zone of high pressure decays (Figure 26). The initial value of this upper limit depends only on the magnitude of slip and the porosity and is independent of any transport properties such as fracture size, density or the detailed nature of the fracture/matrix hydrodynamic coupling. For less porous rocks typical of the Topopah Springs or Tiva Canyon formations $(n \approx 0.10)$ the upper limit of $50 \mathrm{cu}$. $m$. of water produced per $m$. of fault length may be reduced to less than $10 \mathrm{cu} . \mathrm{m}$. per $\mathrm{m}$. of fault length.

\section{Conclusions}

The seismic pumping mechanism may indeed produce sufficient pressures to support a head of over $200 \mathrm{~m}$, but the water table response in our matrix flow models produced water table excursions of 2-14 $\mathrm{m}$ for the dike and normal fault cases. Only by including vertical enhancement in permeability of up to $10^{4}: 1$ was the greater 
end of this range achievable. The amplitudes of water table excursions obtained with these models seem to be consistent with the observations of water table changes associated with large earthquakes. For example, the Dixie Valley - Fairview earthquake of 1954 produced water table excursions of about $4-11$ feet $\left(\begin{array}{lll}1 & -3 \mathrm{~m}\end{array}\right)$ (Raney, 1988) while the 1983 Borah Peak event caused increases of about $4 \mathrm{~m}$ (see Dudley, 1990).

Water transport will not be limited to matrix flow only. A stress change can drive water from the rock matrix to flow through a network of fractures. This would seem to optimize the potential for seismic pumping since most of the ground water is stored in the matrix and fractures are pathways that reduce diffusive losses. Our simple model for a zone of high pore pressure permeated by a network of vertical fractures provides an upper bound on how much water might be pumped. For a major earthquake, we found that negligible to vanishing amounts of water would be transported to the $250 \mathrm{~m} \mathrm{level}$ if the fracture system consisted of the largest fractures commonly observed in core samples (27 microns). The presence of even larger fractures will obviously increase the amount that reaches this level. There is, however, an upper bound on the quantity that is available to be pumped to the $250 \mathrm{~m}$ level. We argue that this bound correponds to that quantity pressurized to values above 25 bars, the pressure needed to support a $250 \mathrm{~m}$ column of water. As the pore pressure decays this bound also decreases and ultimately vanishes when pore pressures fall below the critical 25 bar value. An extreme value of this bound was found to be $50 \mathrm{cu} . \mathrm{m}$. of water per $m$. of fault length assuming $n=0.46$ for the matrix 
porosity. Using a more typical value for of $n=0.10$, which is characteristic of the Topopah Springs unit, a bound of $10 \mathrm{cu}$. m. per $\mathrm{m}$. of fault length is obtained. 


\section{Beferences}

Atkinson, B.K. and Meredith, P.G., The Theory of Subcritical Crack Growth with Applications to Minerals and Rocks, in Fracture Mechanics of Rock edited by Barry Kean Atkinson, Academic Press Geology Series, 534 pages, p. 111-166, 1987.

Barr, G.E. and Miller, W.B., Simple Models of the Saturated Zone at Yucca Mountain, Sandia National Laboratories Report, SAND87-0112, 84 pages, 1987.

Bilham, R.G., and King, G.C.P., 1989, The Morphology of Strike Slip Faults; Examples from the San Andreas. Journal of Geophysical Research. 94, B8, pp. 10204-10216.

Bixler, N.E., NORIA- A Finite Element Computer Program for Analyzing Water, Vapor, Air and Energy Transport in Porous Media. Sandia National Laboratories Report, SAND84-2057, 115 pages, 1985.

Brune, J., Seismic Moment, Seismicity and Rate of Slip Along Major Fault Zones. J. Geophys. Res., 73, 779, 1968.

Buscheck, Thomas A. and Nitao, John J., Estimates of the Width of the Wetting Zone Along a Fracture Subjected to an Episodic Infiltration Event in Variably Saturated, Densely Welded Tuff. Lawrence Livermore Informal Document UCID-21579, 54 pages, 1988.

Crouch, S.L. and Starfield, A.M., Boundary Element Methods in Solid Mechanics, Allen and Unwin Publishers, London, 322 pages, 1983.

Czarnecki, J.B. and Wadell, R.K., Finite Element Simulation of Ground Water Flow in the Vicinity of Yucca Mountain, Nevada - California. U.S. Geological Survey Water-Resources Investigations Report, 844349, 1984.

Davis, Paul M. , Surface Deformation Associated with a Dipping Hydrofracture. J. Geophys. Res., 88, 5826-5834, 1983.

Dudley, W.W., Barr, G.E., Chesnut, D.A. and Fridrich, C.J., Eds., Review of a Conceptual Model and Evidence for Tectonic Control of the Ground-Water System in the Vicinity of Yucca Mountain, Nevada. U.S. Denartment of Fnernv. Yurc.a Mnusntain Prniert Office. 1.33 nanes. 
Dudley, William W., Multidisciplinary Hydrologic Investigations at Yucca Mountain, Nevada. Proceedings of the International Topical Meeting on High Level Radloactive Waste Management, 1, 1-9, 1990.

Engelder, Terry, Joints and Shear Fractures in Rock, in Eracture Mechanics of Rock edited by Barry Kean Atkinson, Academic Press Geology Series, 534 pages, 27-69, 1987.

Frank, F.C., On Dilatancy in Relation to Seismic Sources. Rev. Geophys, 3, 484-503, 1965.

Hackman ,C., King, G.C.P., and Bilham, R.G., 1989, An Examination of the Structure of the South Iceland Seismic zone Using Boundary Element Methods. Journal of Geophysical Research. (in press)

Jackson, Dallas B. and Kauahikaua, James, Regional Self-Potential Anomalies at Kilauea Volcano, U.S. Geological Survey Professional Paper 1350, 2, 947-959, 1987.

Johnson, A.G., Kovach, R.L., Nur, A. and Booker, J.R., Pore Pressure Changes During Creep Events on the San Andreas Fault, J. Geophys. Res., 78, 851-857, 1973.

Johnson, A.G., Kovach, R.L. and Nur, A., Fluid-Pressure Variations and Fault Creep in Central California, Tectonophysics, 23, 257-266, 1974.

King, G.C.P., and Sammis, C.,1990, The Mechanisms of Finite Brittle Strain. PAGEOPH. (in press)

King, G.C.P., and Ellis, M., 1990, The Origin of Large Local Uplift and Flank Vulcanism in Extensional Reglons. Nature (in review)

King, G.C.P., Sturdy, D., and Whitney, J., 1990; 'The Landscape Geometry and Active Tectonics of N.W. Greece. GSA Bull. (in review)

Klavetter, Elmer A. and Peters, Ralph R., Estimation of Hydrologic Properties of an Unsaturated, Fractured Rock Mass. Sandia National Laboratories Report, SAND84-2642, 1986.

Kranz, R. L., Microcracks in Rocks: A Review, Tectenephysics, $100,449-480,1983$. 
Lippinoott, Diane K., Bredehoeft, John D. and Moyle, W.R., Recent Movement on the Garlook Fault as Suggested by Water Level Fluctuations in a Well in Fremont Valley, California. J. Geophys. Res., 90, 1911-1924. 1985.

Maulem, Y., A New Model for Predicting Hydraulic Conductivity of Unsaturated Porous Materials, Water Resources Research, 12, 513$522,1976$.

Nur, A., Dilatancy, Pore Fluids and Premonitory Variations of $t_{s} / t_{p}$ Travel Times. Bull. Seismol. Soc. Am., 62, 1217-1222.

Raleigh, C.B., Healy, J.H. and Bredehoeft, J.D., Faulting and Crustal Stress at Rangely, Colorado in Elow and Fracture in Rocks (The Griggs Volume), H.C. Heard, I.Y. Borg, N.L. Carter and C.B. Raleigh, Eds. Geophsical Monograph 16, American Geophysical Union, 275-284, 1972.

Raney, Russell G., Reported Effects of Selected Earthquakes in the Western North American Intermontane Region, 1852-1983, on Underground Workings and Local and Regional Hydrology: A Summary. U.S. Department of the Interior, Bureau of Mines Report, NRC FIN D1018, 114 pages, 1988.

Roark, Raymond J., Formulas for Stress and Strain. McGraw-Hill, New York, 2nd Edition, 366 pages, 1943.

Roeloffs, E., and Rudnickl, J.W., Couped-Deformation Diffusion Effects on Water Level Changes Due to Propagating Creep Events. Pure Appl. Geophys., 122, 560-582, 1984.

Rudnicki, J.W. and Hsu, T.C., Pore Pressure Changes Induced by Slip on Permeable and Impermeable Faults. J. Geophys. Res., 93, 3275-3285, 1988.

Rundle, J.B., Derivation of the Complete Gutenberg-Richter Magnitude-Frequency Relation Using the Principle of Scale Invariance. J. Geophys. Res., 94, 12337-12342, 1989.

Sibson, R.H., Moore, J. McM. and Rankin, A.H., Seismic Pumping - A Hydrothermal Fluid Transport Mechanism. J. geol. Soc. Lond., 131, 653-659, 1975. 
Szymanskl, J., Conceptual Considerations of the Yucca Mountain Groundwater System with Special Emphasis on the Adequacy of this System to Accommodate a High-Level Nuclear Waste Repository, U.S. Department of Energy, Nevada Operations Office, Yucca Mountain Project Office, 390 pp., 1989.

URS/Blume and Associates, Technical Basis and Parametric Study of Ground Motion and Surface Rupture Hazard Evaluations at Yucca Mountain, Nevada. Sandia National Laboratories Report, SAND867013, 99 pages, 1987.

van Genuchten, M. Th., Calculating the Unsaturated Hydraulic Conductivity with a New Closed-Form Analytical Model, Water Resources Bulletin, Princeton Univ. Press, Princeton Univ., Princeton, N.J., 1978

Wesson, Robert L., Interpretation of Changes in Water Level Accompanying Fault Creep and Implications for Earthquake Prediction. J. Geophys. Res., 86, 9259-9267, 1981.

Zheng, Ziqiong, Compressive Stress-Induced Microcracks in Rocks and Applications to Seismic Anisotropy and Borehole Stability, Dissertation submitted to U.C. Berkeley, Dept of Material Science and Mineral Engineering, 277 pages, 1989. 
Table 1

Physical Constants Used In Models

$\begin{array}{lll}\text { Parameter } & \text { Symbel } & \text { Value } \\ \begin{array}{l}\text { Density (water) } \\ \text { Dynamic Viscosity }\end{array} & \rho_{w} & 1.0 \times 10^{3} \mathrm{~kg} / \mathrm{m}^{3} \\ \text { (water) } & \mu & 1.0 \times 10^{-3} \mathrm{~N} \mathrm{~s} / \mathrm{m}^{2} \\ \text { Grav. Accel. } & \mathrm{g} & 9.8 \mathrm{~m} / \mathrm{s}^{2} \\ \text { Density (CHv) } & \rho_{m} & 2.37 \times 10^{3} \mathrm{~kg} / \mathrm{m}^{3} \\ \text { Young's Modulus } & \mathrm{E} & 1.58 \times 10^{10} \mathrm{nt} / \mathrm{m}^{2} \\ \text { Poisson's Ratio } & v & 0.17-0.28 \\ \text { Porosity (CHv) } & \mathrm{n} & 0.46 \\ \text { Hydraulic Cond. } & \mathrm{K}_{\mathrm{m}} & 2.7 \times 10^{-7} \mathrm{~m} / \mathrm{s} \\ \text { Residual Saturation } & \mathrm{S}_{\mathrm{r}} & 0.041 \\ \text { Const. in Eq. 4 (CHv) } & \alpha & 1.6 \times 10^{-2} \mathrm{~m}-1 \\ \text { Const. in Eq. 4 (CHv) } & \beta & 3.87 .2 \\ \text { Fault Slip } & \varepsilon & 0.1-1.0 \mathrm{~m}\end{array}$




\section{List of Figures}

Figure 1. Cartoon showing relationship between geometry of $10 \mathrm{~km}$ dilatant zone and high permeabllity fault zone into which all available ground water flow (dashed arrows) is channeled.

Figure 2. Flow chart illustrating prooedure for obtaining water table response as a function of fault/dlke geometry displacements.

Figure 3. Volumetric strain field for a $2 \mathrm{~m}$ dike emplaced $750 \mathrm{~m}$ below the surface. Shades of white to gray indicate regions of compression and shades of black to gray indlcate dilatancy. The area within the black frame is the domain of the hydrologic model.

Figure 4. Pore pressure proflles across 2 and $4 \mathrm{~m}$ dikes.

Figure 5. Position of the water table as a function of time (see legend) for intrusion of a $2 \mathrm{~m}$ wide dike into a medlum with isotropic permeability.

Figure 6. Same as Fig. 5 except the medlum has a 10:1 enhancement of vertical permeability.

Figure 7. Water table response for $2 \mathrm{~m}$ dike in $100 \mathrm{~m}$ wide zone of vertical permeability enhancement. Vertical permeability is enhanced from 10:1 to $104: 1$ over horizontal values. Maximum water table response is included for isotroplo case for comparison.

Figure 8. Same as Fig. 7 except for $4 \mathrm{~m}$ dike with vertical permeability enhancement of 10:1 - 103:1.

Figure 9. Moisture content for the isotropic case of the vadose zone in a column above the $2 \mathrm{~m}$ dike at $\mathrm{t}=0$. and at the time corresponding to the maximum excursion of the water table.

Figure 10. Same as Fig. 9 except for case of $2 \mathrm{~m}$ dike in $100 \mathrm{~m}$ wide region of vertical permeabllity enhancement $(10: 1)$.

Figure 11. Volumetric strain distribution for $1 \mathrm{~m}$ of slip on normal tault (dashed line) locked $750 \mathrm{~m}$ below surface $(250 \mathrm{~m}$ below water table). Region in black frame is domain of hydrologic model.

Figure 12. Horizontal volumetric strain profile at water table level for $1 \mathrm{~m}$ slip case assuming two different values of Polsson's ratio. 
Figure 14. Surface of water table $(S=0.99)$ at three different times for an $0.1 \mathrm{~m}$ sllp event. Solld line corresponding to final time is maximum exoursion of water table surface.

Figure 15. Same as Fig. 14 exoept for $0.25 \mathrm{~m}$ slip event.

Figure 16. Same as Flg. 14 except for $0.5 \mathrm{~m}$ slip event.

Figure 17. Same as Fig. 14 exoept for $1.0 \mathrm{~m}$ sllp event.

Figure 18. Plot of maximum water table rise as a function of slip on normal fault.

Figure 19. Plot of maximum water table rise as a function of earthquake magnitude. $1 \mathrm{~m}$ slip corresponds to $m=7.4$.

Figure 20. Water table response for reglonal vertical permeabllity enhancements of from 10 to $10^{3}$. Isotroplo oase included for comparison.

Figure 21. Water table response for local vertical permeability enhanoement (10 to 103) with anisotroplo region centered around normal fault.

Figure 22. Contours of decaying region of pore pressures exceeding 25 bars. Region vanishes in less than one day for $\mathrm{CHv}$ properties. Lifetime would increase with lower permeabillties.

Figure 23. Histories of pore pressure at two points in zone of high pore pressures. Location $A$ is point of highest pore pressure. Location $B$ is near polnt of weakest decay.

Figure 24. Spatlal distribution of water pumped to $250 \mathrm{~m}$ level through 27 micron cracks as obtalned from simple fracture flow model.

Figure 25. Plot showing total volume of water ralsed to the $250 \mathrm{~m}$ level as a function of time.

Figure 26. Plot showing quantity of excess ground water as a function of time that is pressurized to values above 25 bars.

Provides upper bound on maximum quantity of water that could be driven by pressure to $250 \mathrm{~m}$ level. Time dependence determined by decay of pore pressure caused by diffusion in matrix. 
FIg. 1

Surface

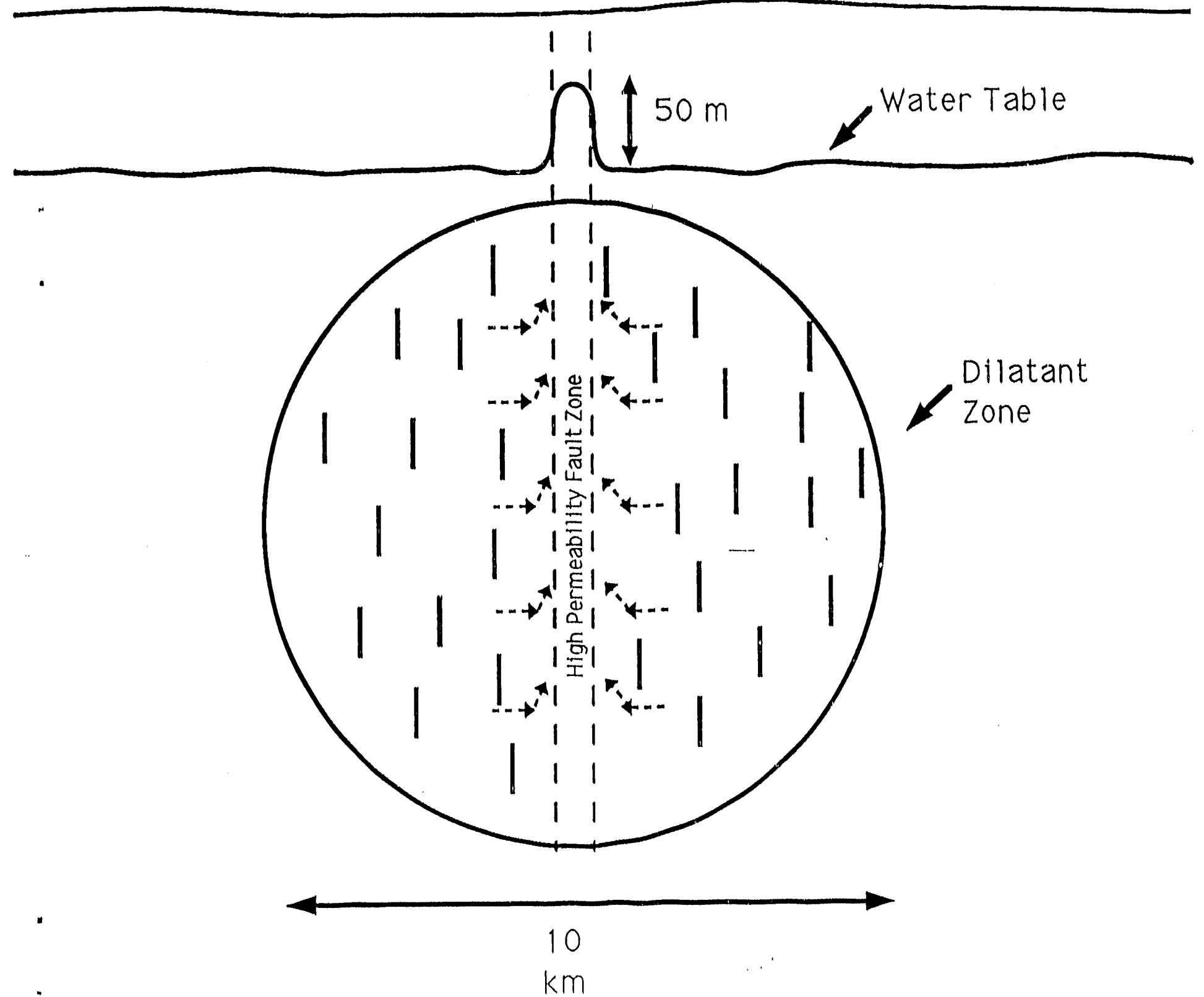




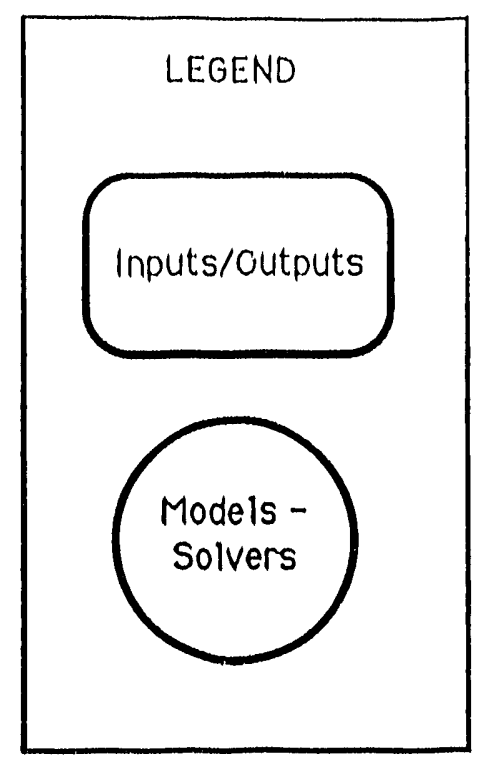

Fault/Dike Geom

Displacements

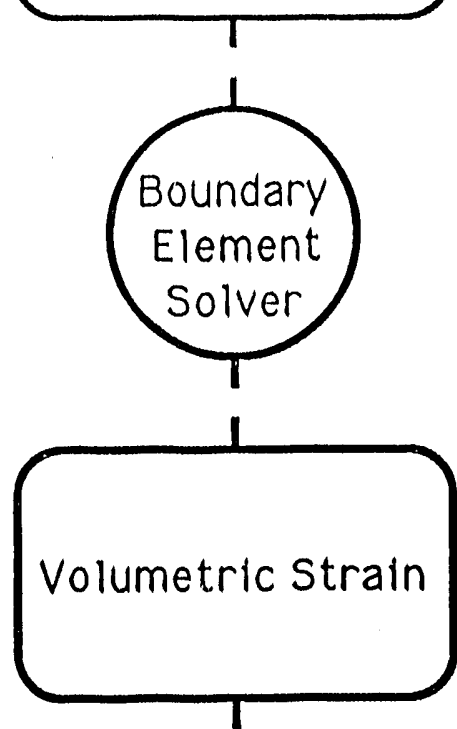

Fig. 2

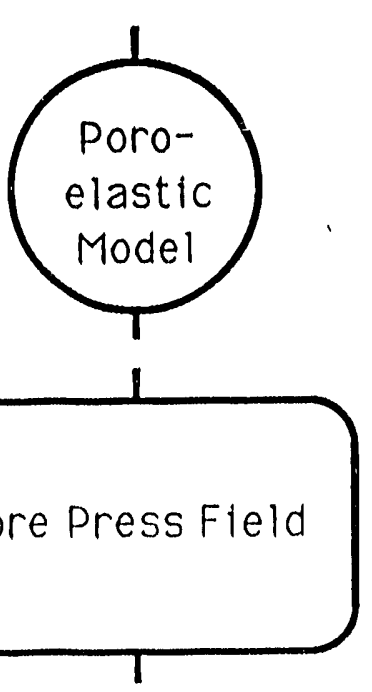

Hydrologic Domain

Phys. Properties

Boundary Cond.

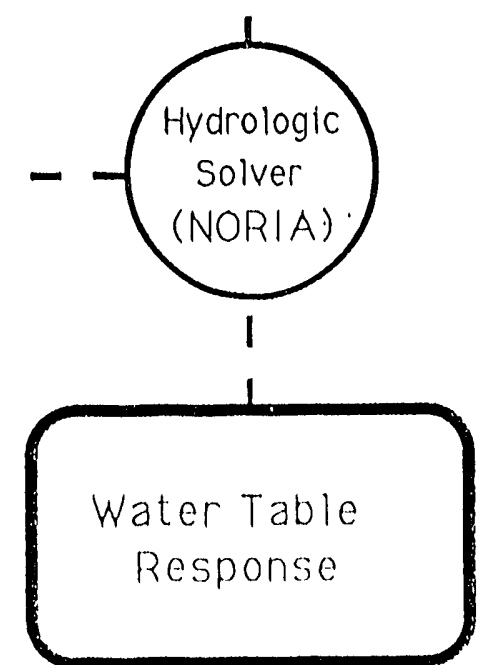


Fig. 3

Overlay of F.E.M. Domain

on Dike Strain Field

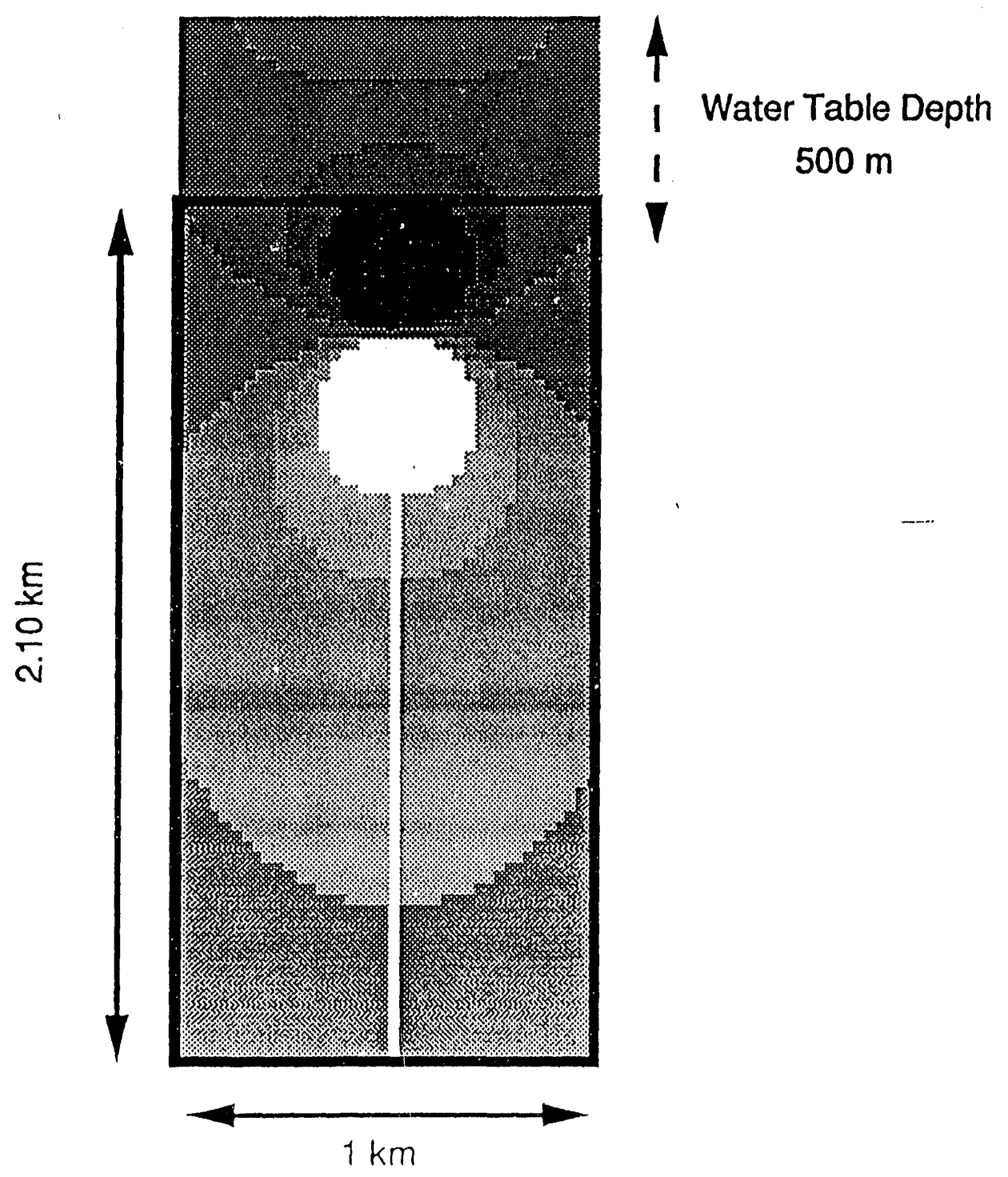


Fig. 4

Pore Pressure Profiles Across Dikes
1 km Depth

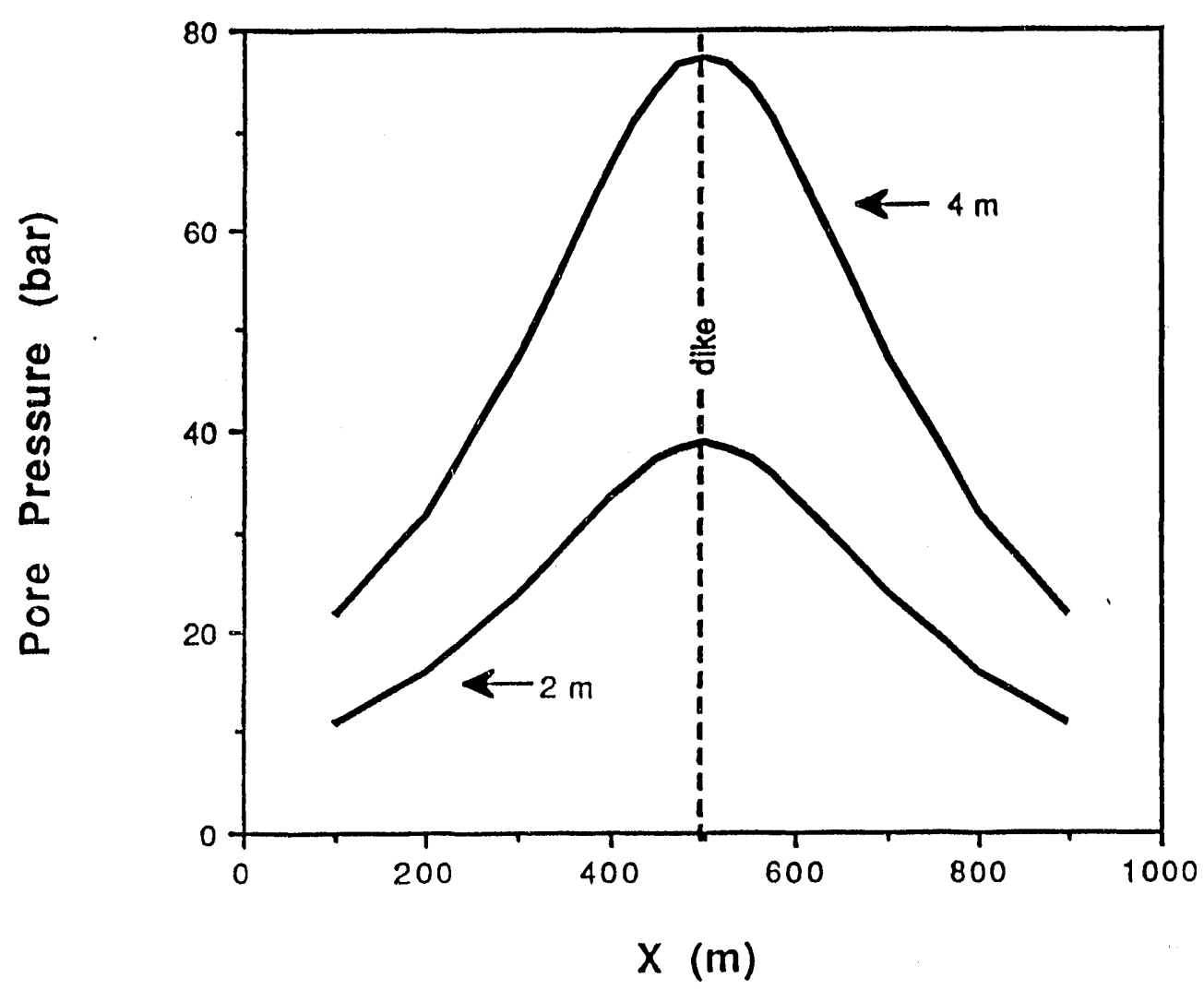




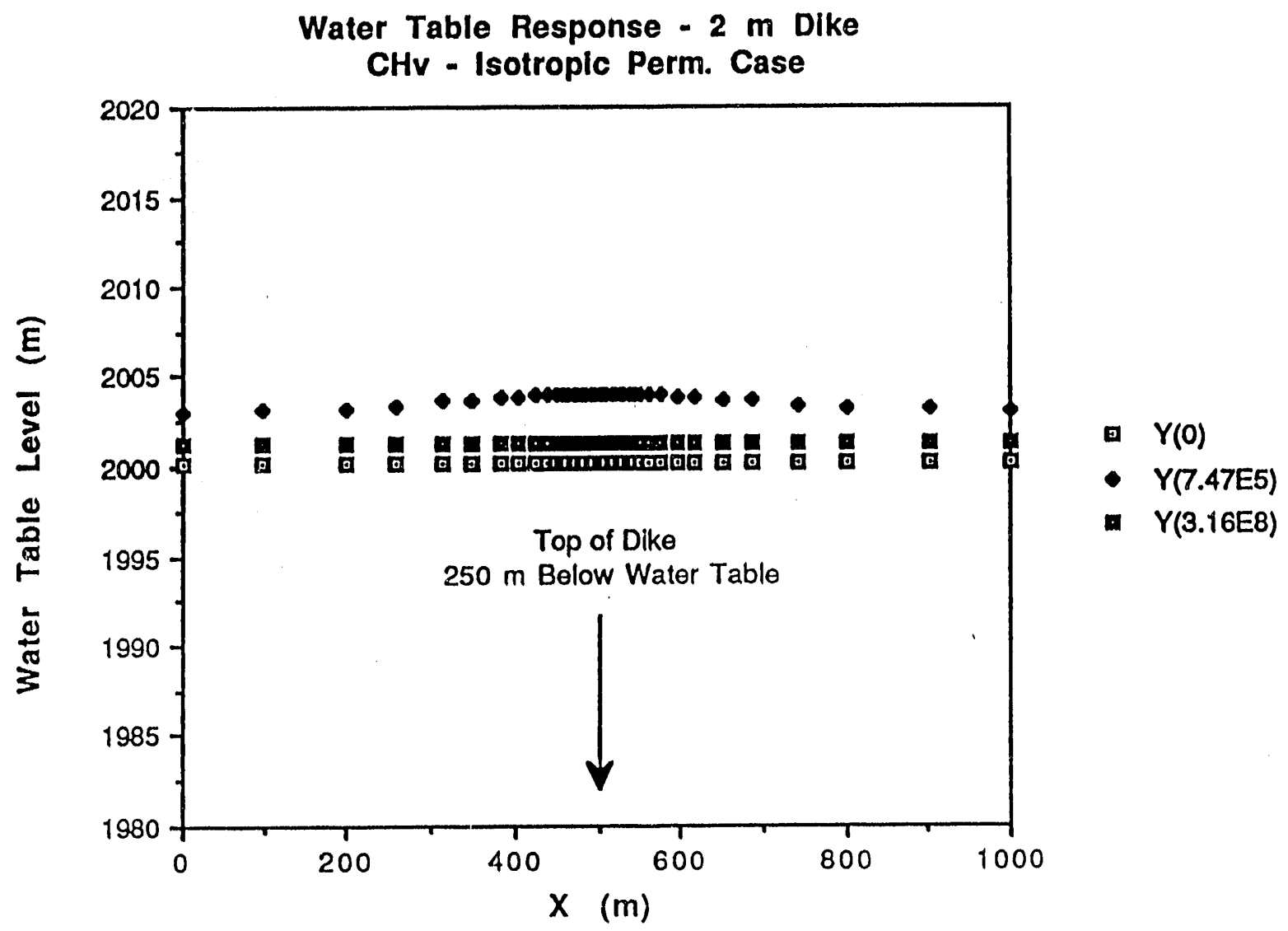

Obtained with $100 \mathrm{~m}$ grid over vadose zone 


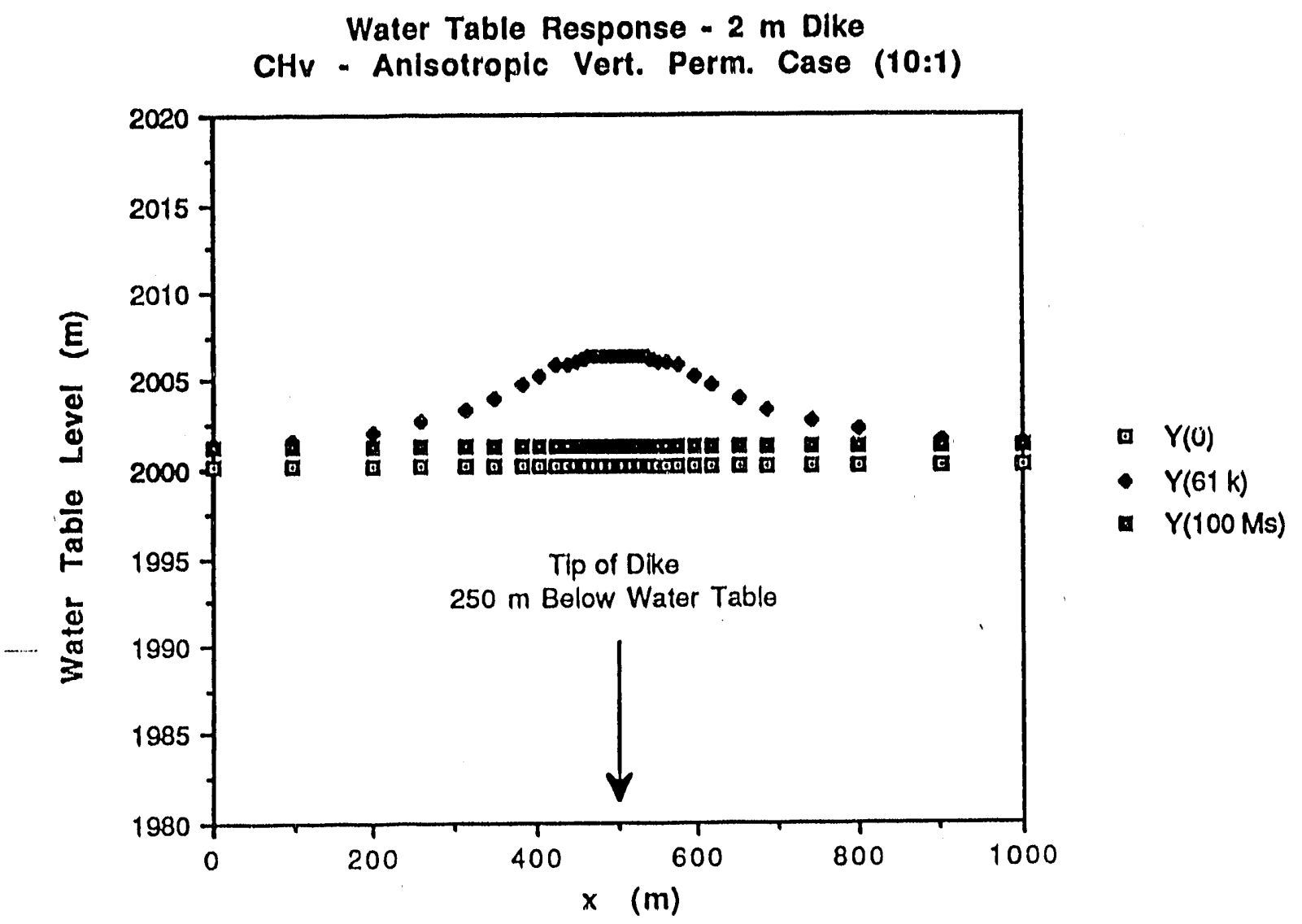

Obtained with $100 \mathrm{~m}$ grid over vadose zone 
Water Table Response - 2 m Dike Different Vertical Perm. Enhancements

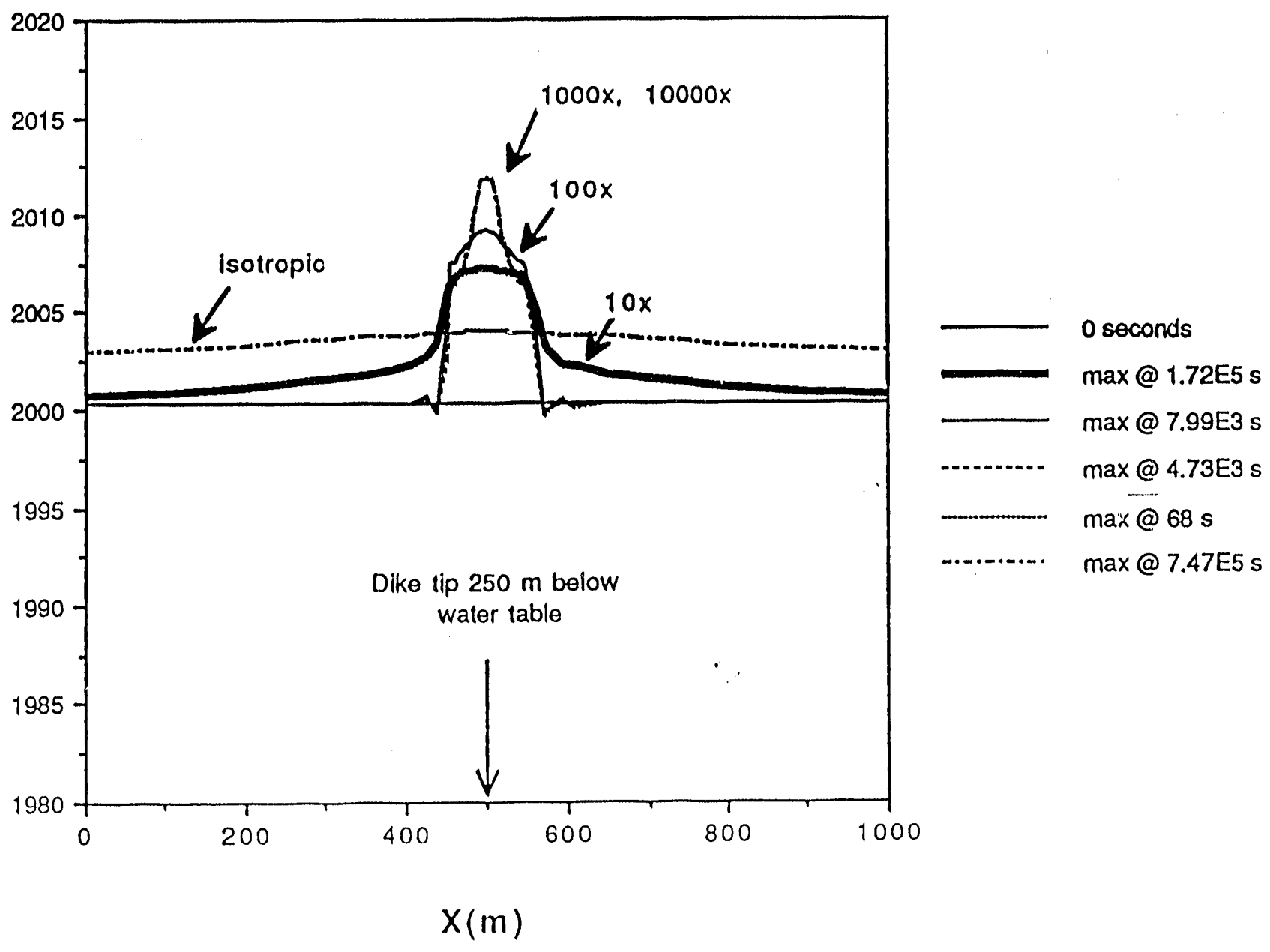




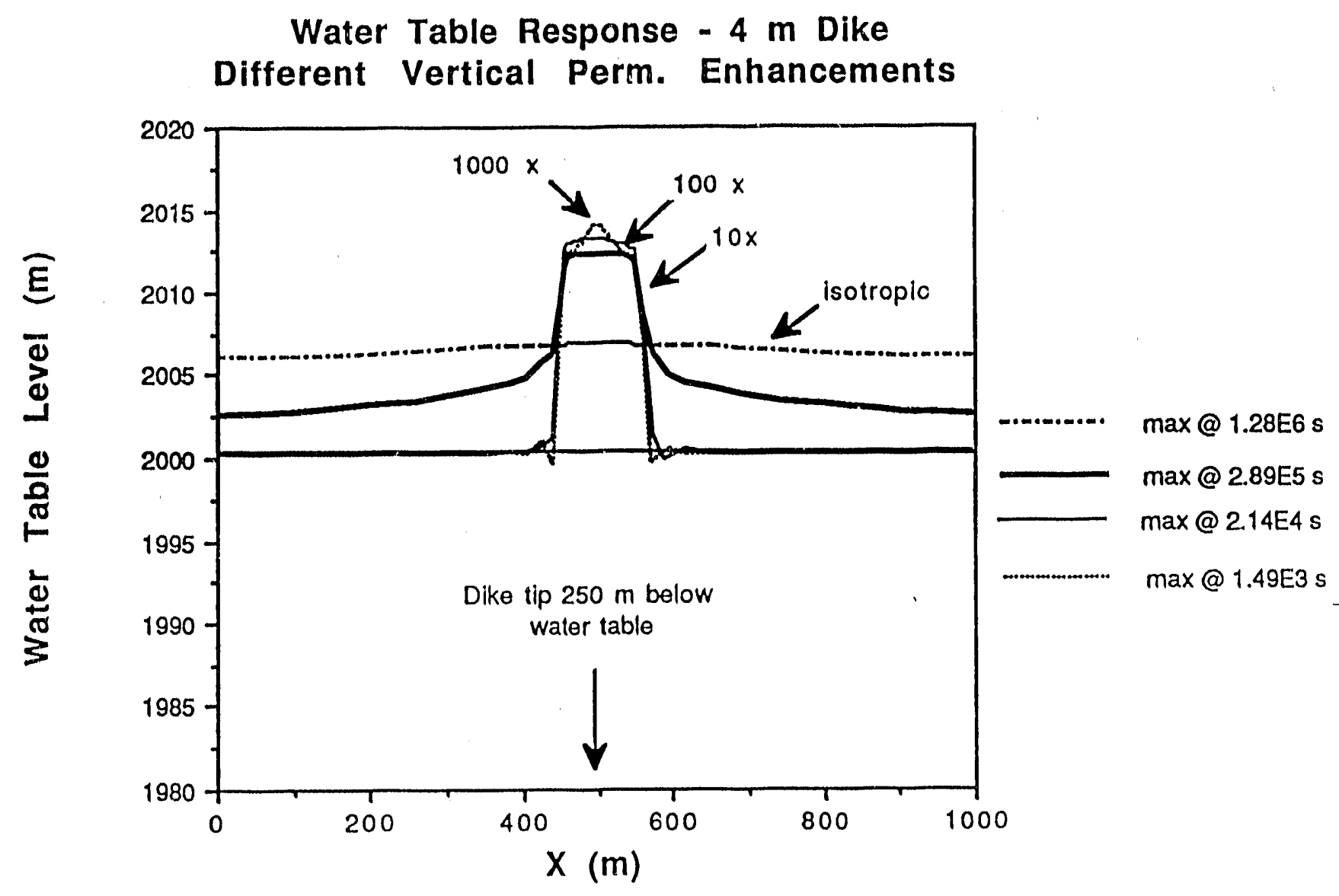


NAg. 9

Molsture Content in Vadose Zone

$\mathrm{CHv}$ - Isotropic Permeability

$2 \mathrm{~m}$ Dike

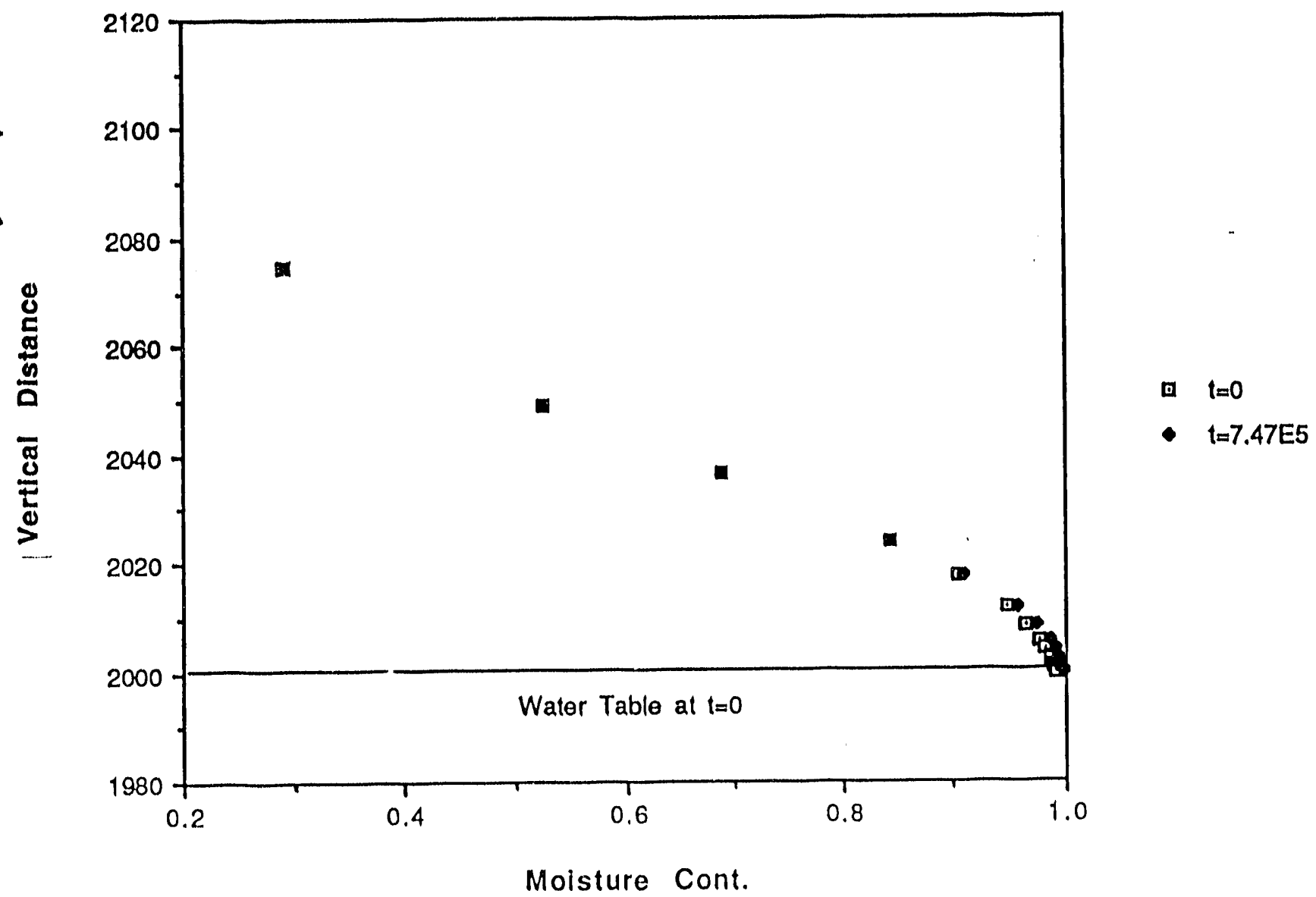




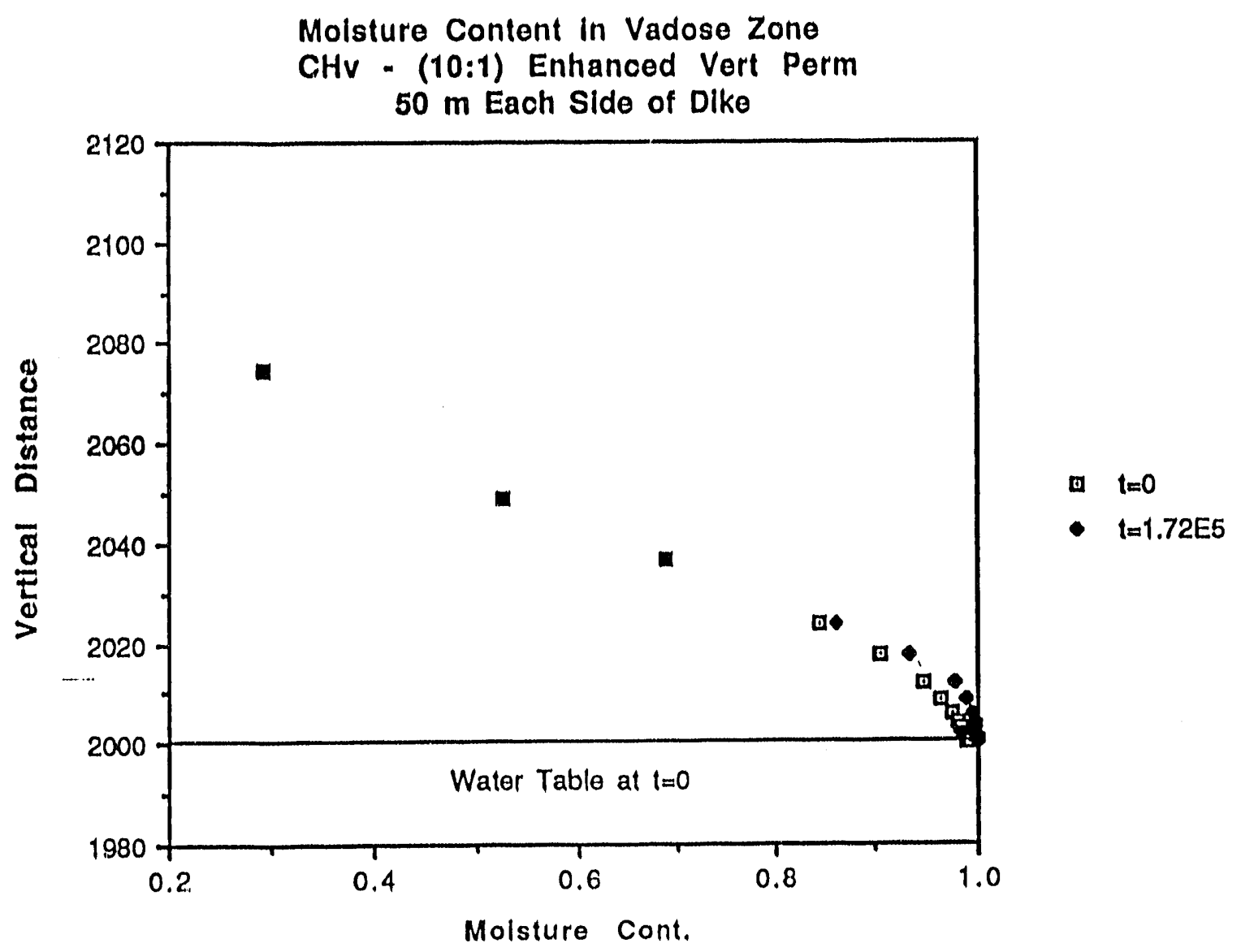


Overlay of F.E.M. Domain on Fault Strain Field

Water Table Depth $500 \mathrm{~m}$
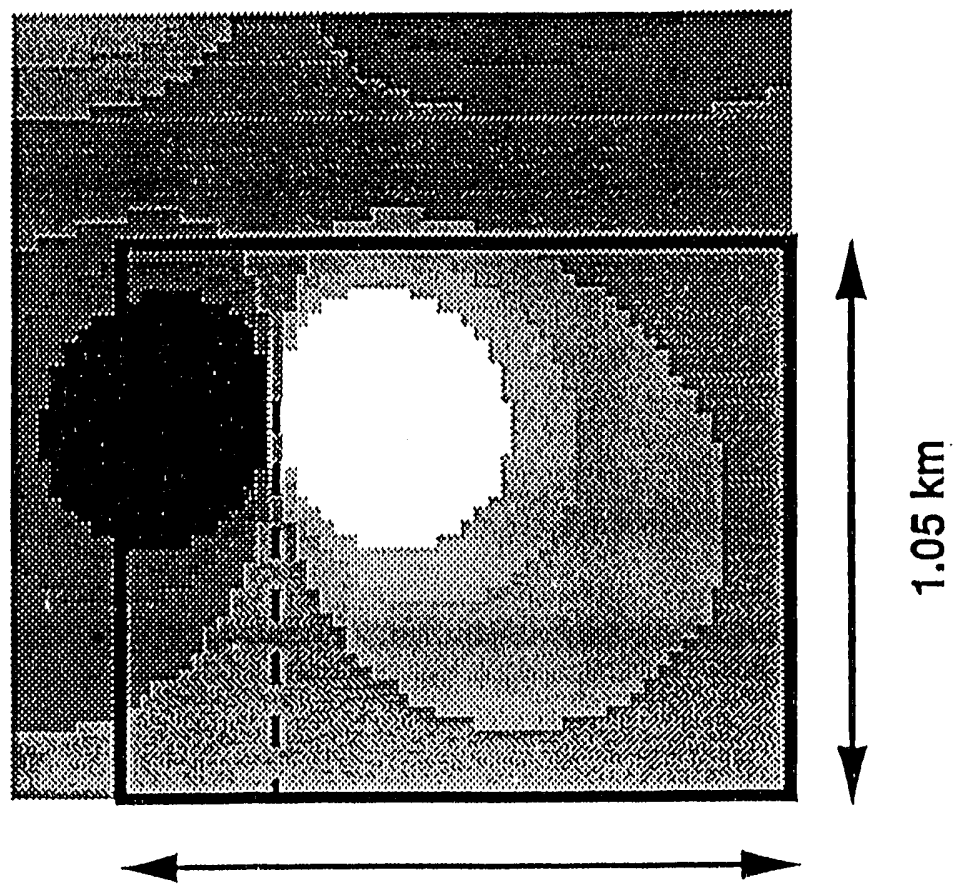

$1.25 \mathrm{~km}$ 
Volumetric Strain Profile at Water Table Level

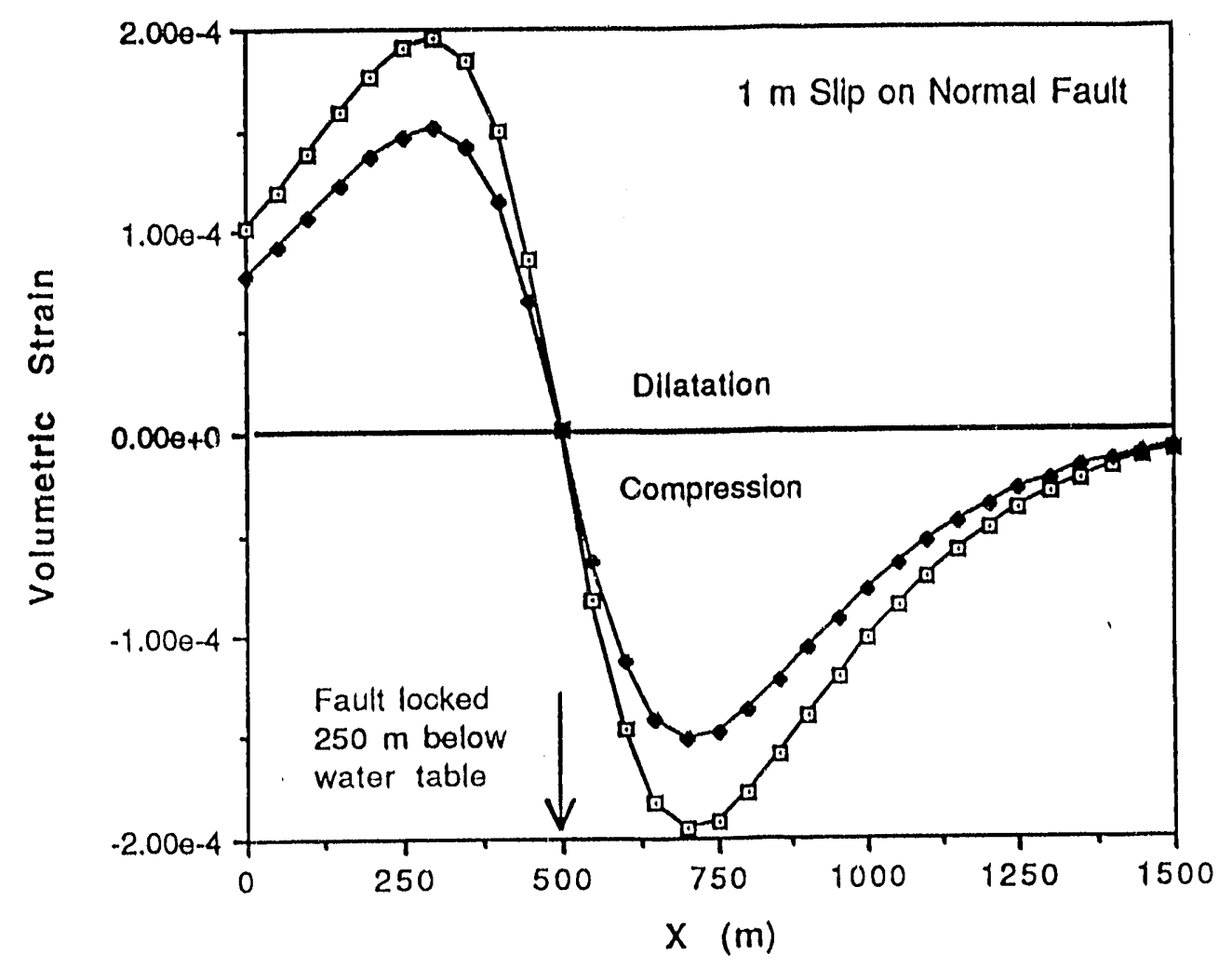

$\longrightarrow$ Poisson $=0.17$

Poisson $=0.28$ 


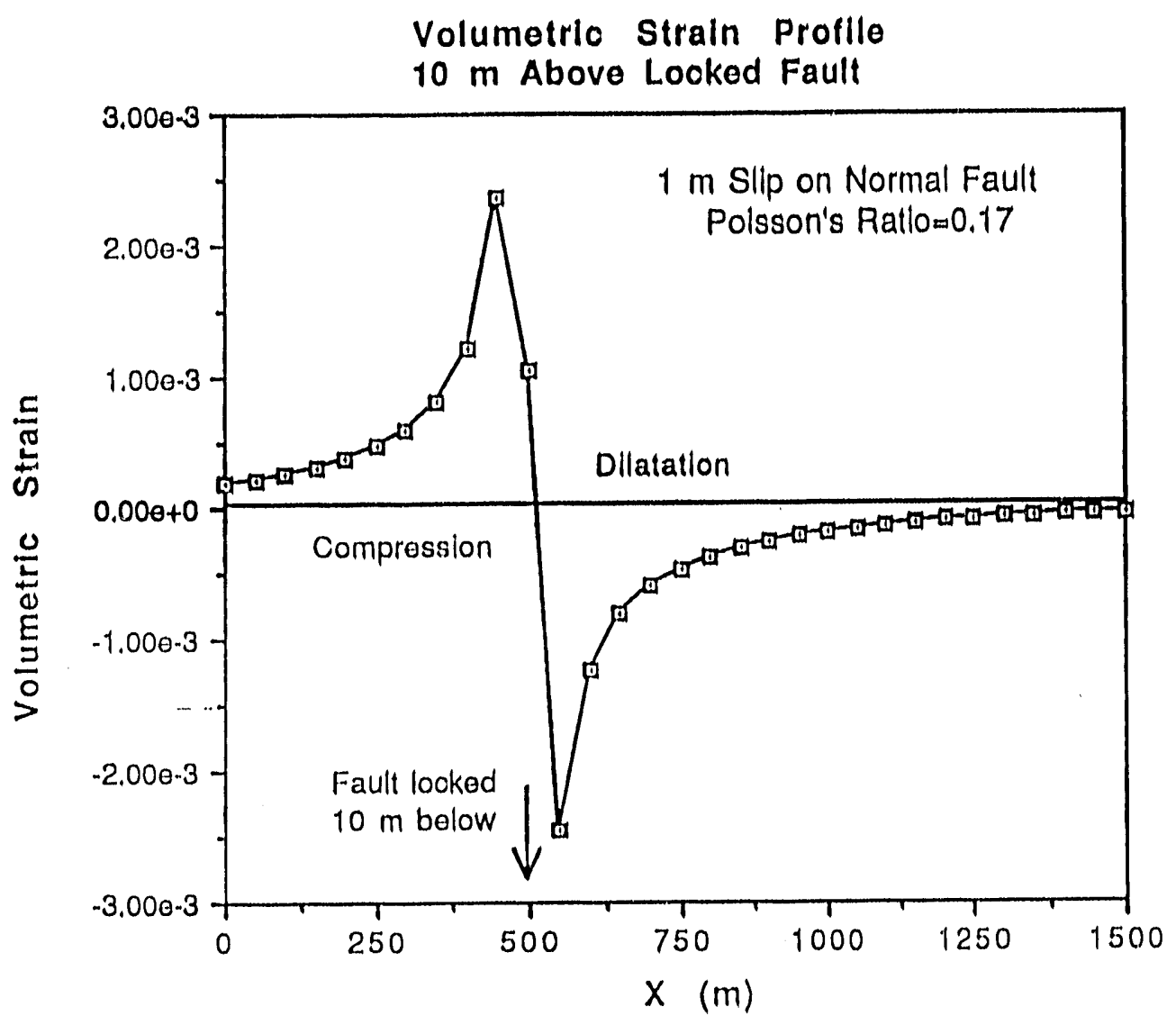


Water Table Response - $0.10 \mathrm{~m}$ Slip Chv - Isotroplc Permeability

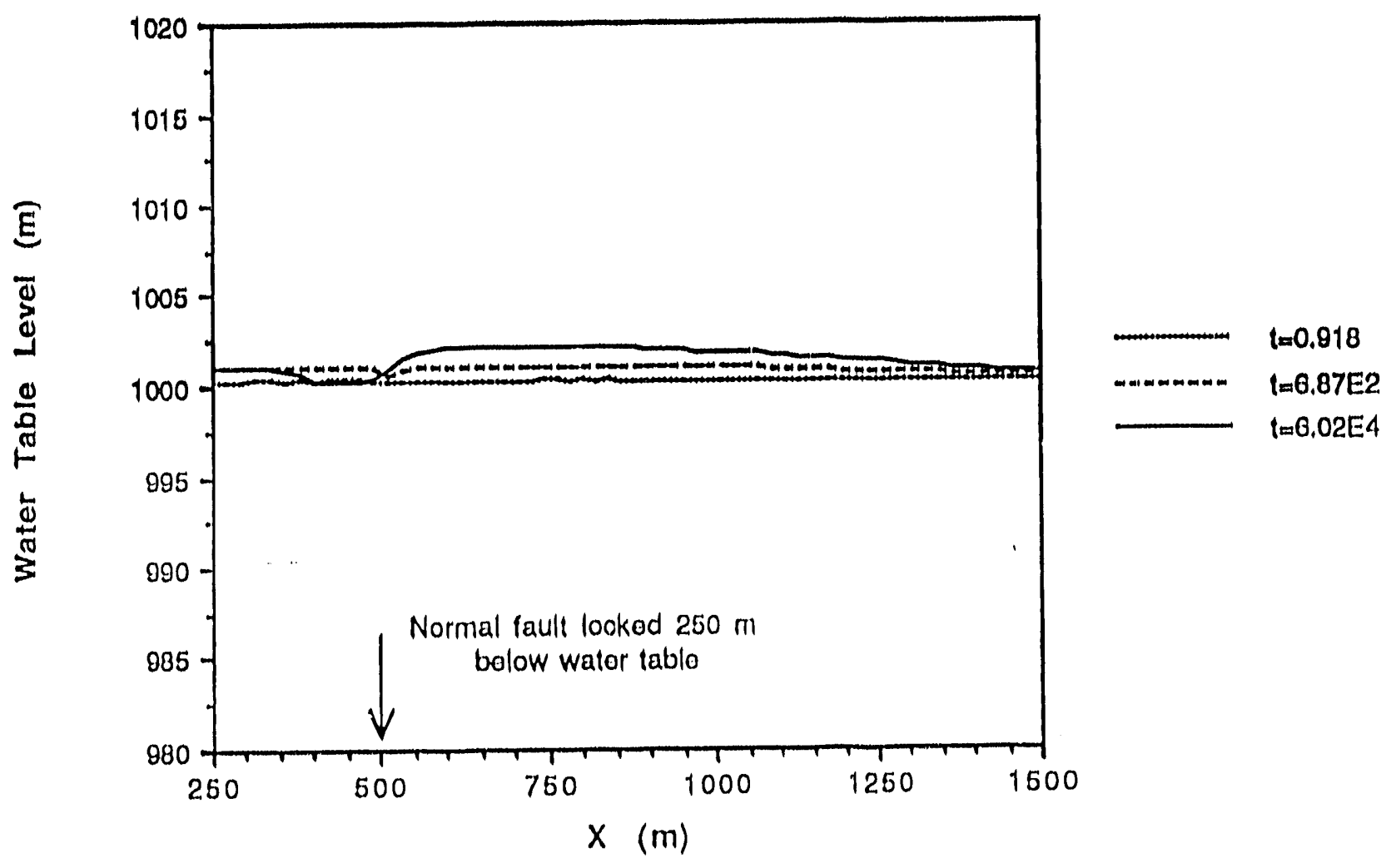




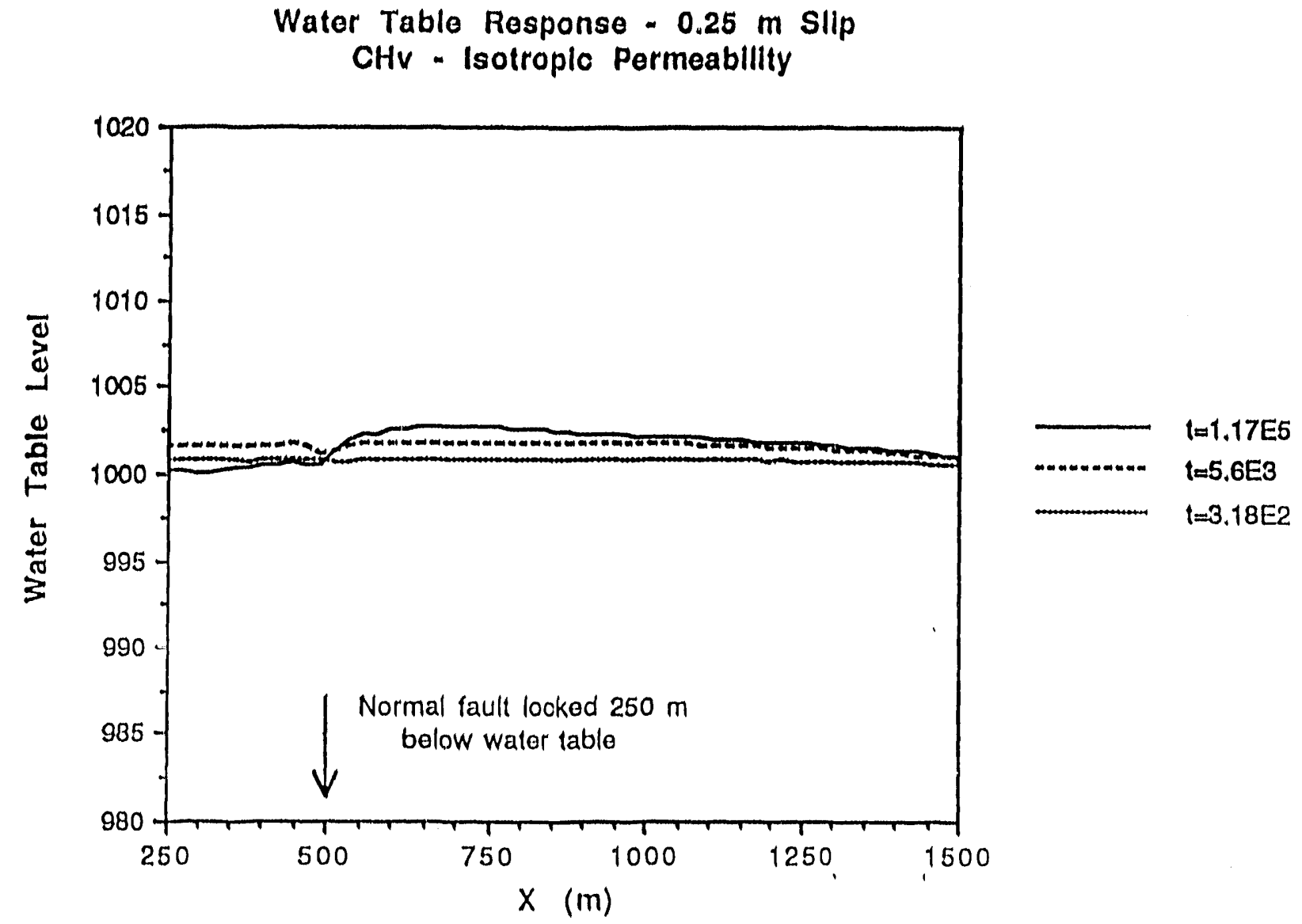




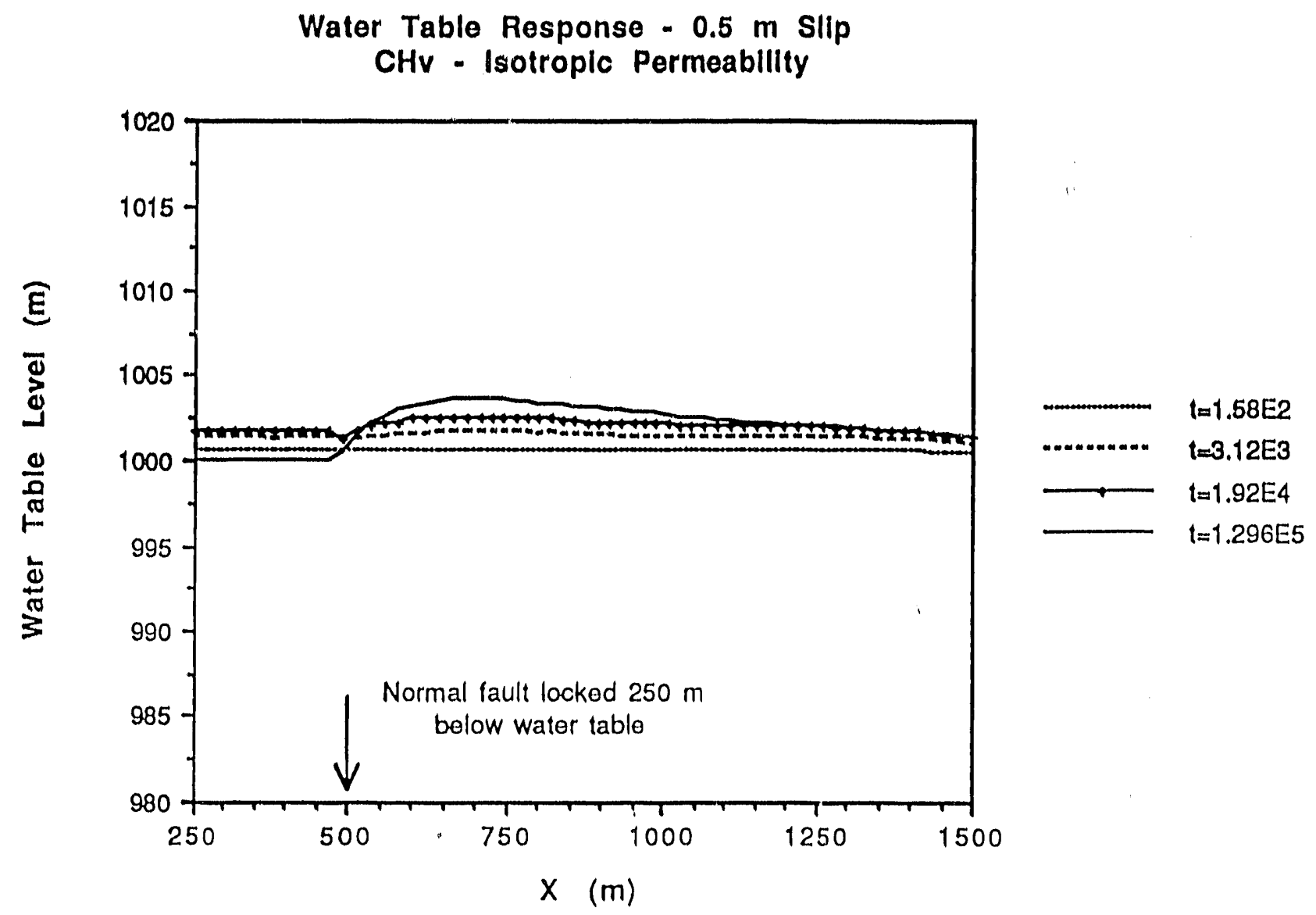


Fig. 17

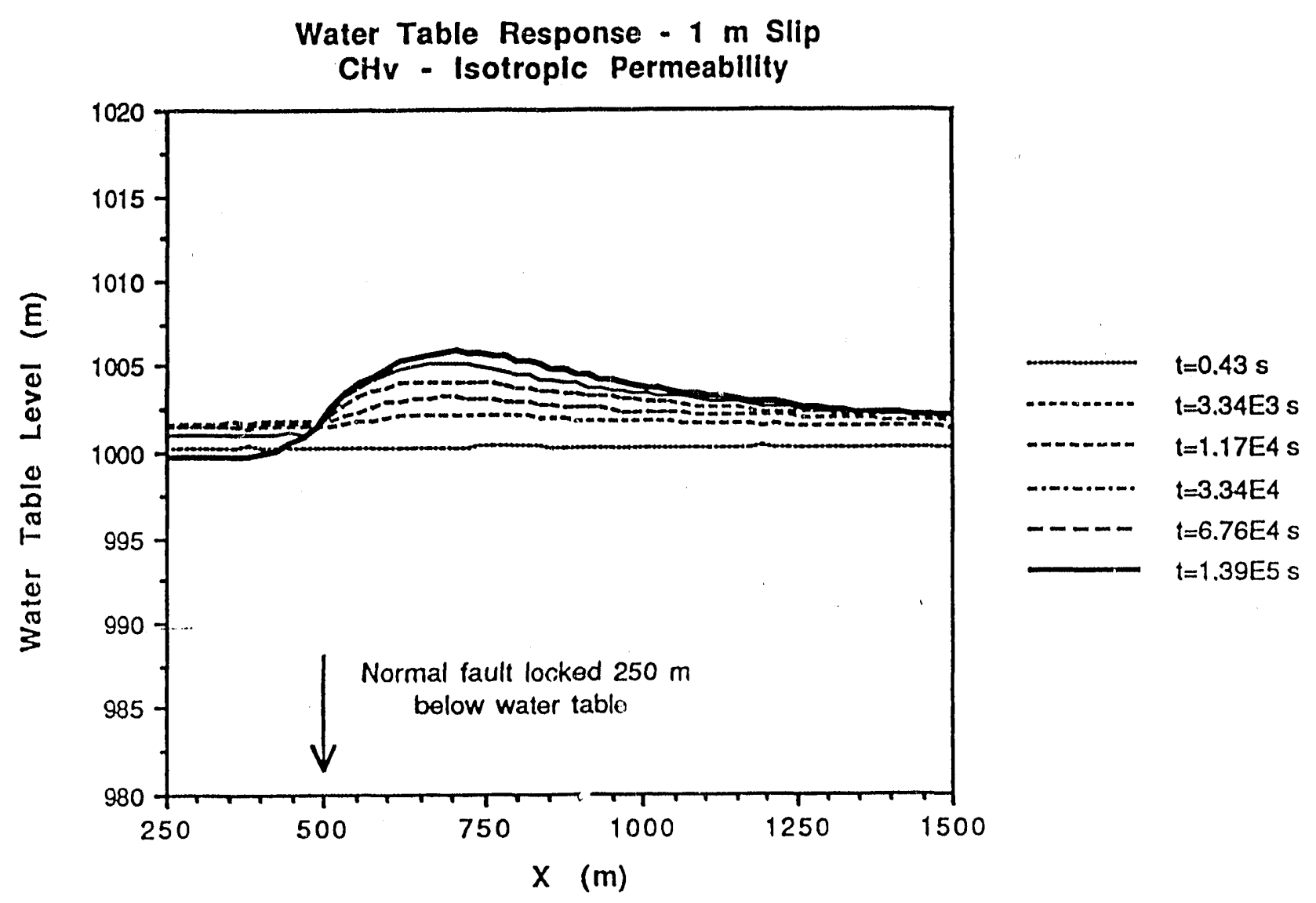




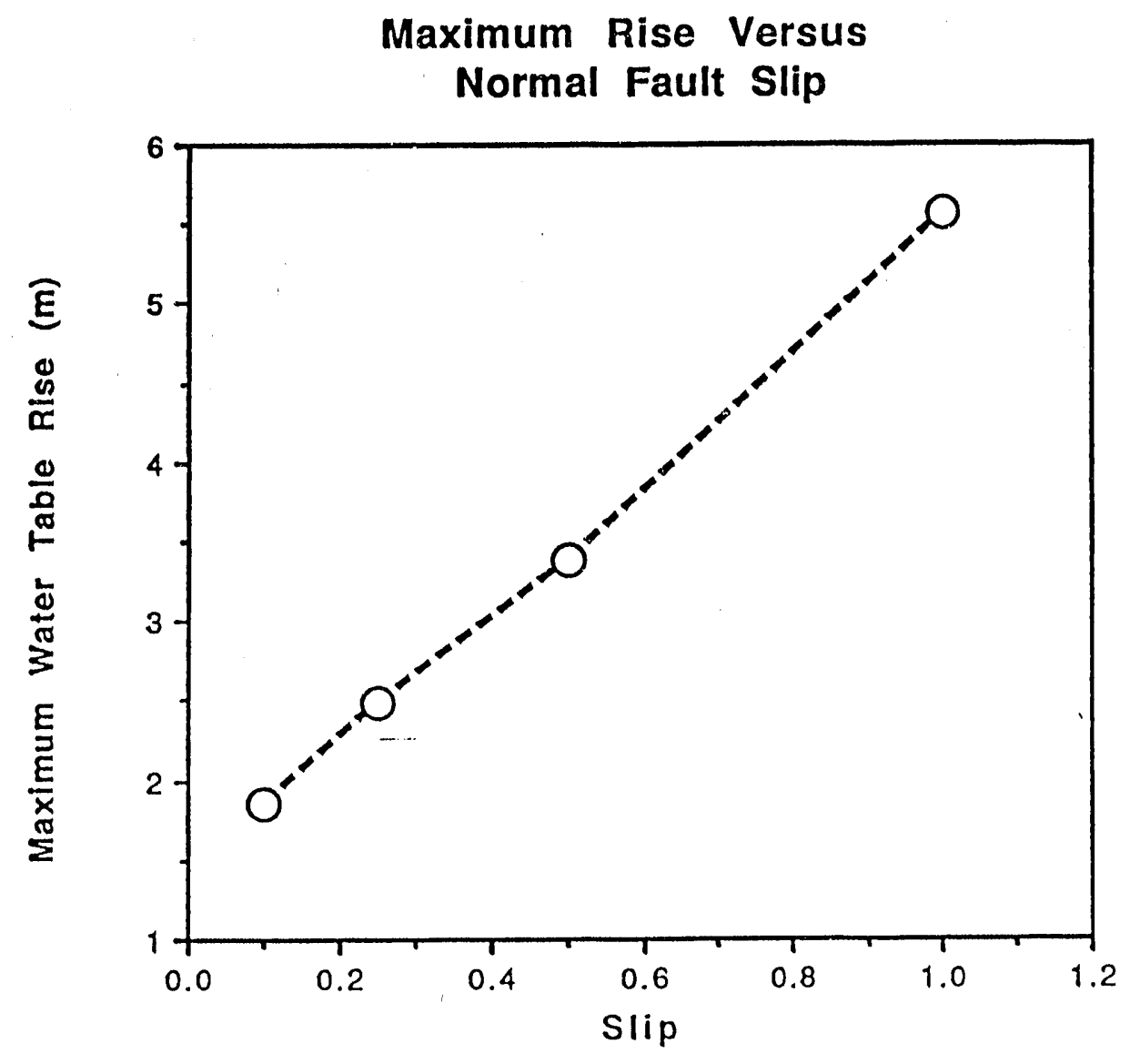


Fig. 19

Maximum Rise Versus

Earthquake Magnitude

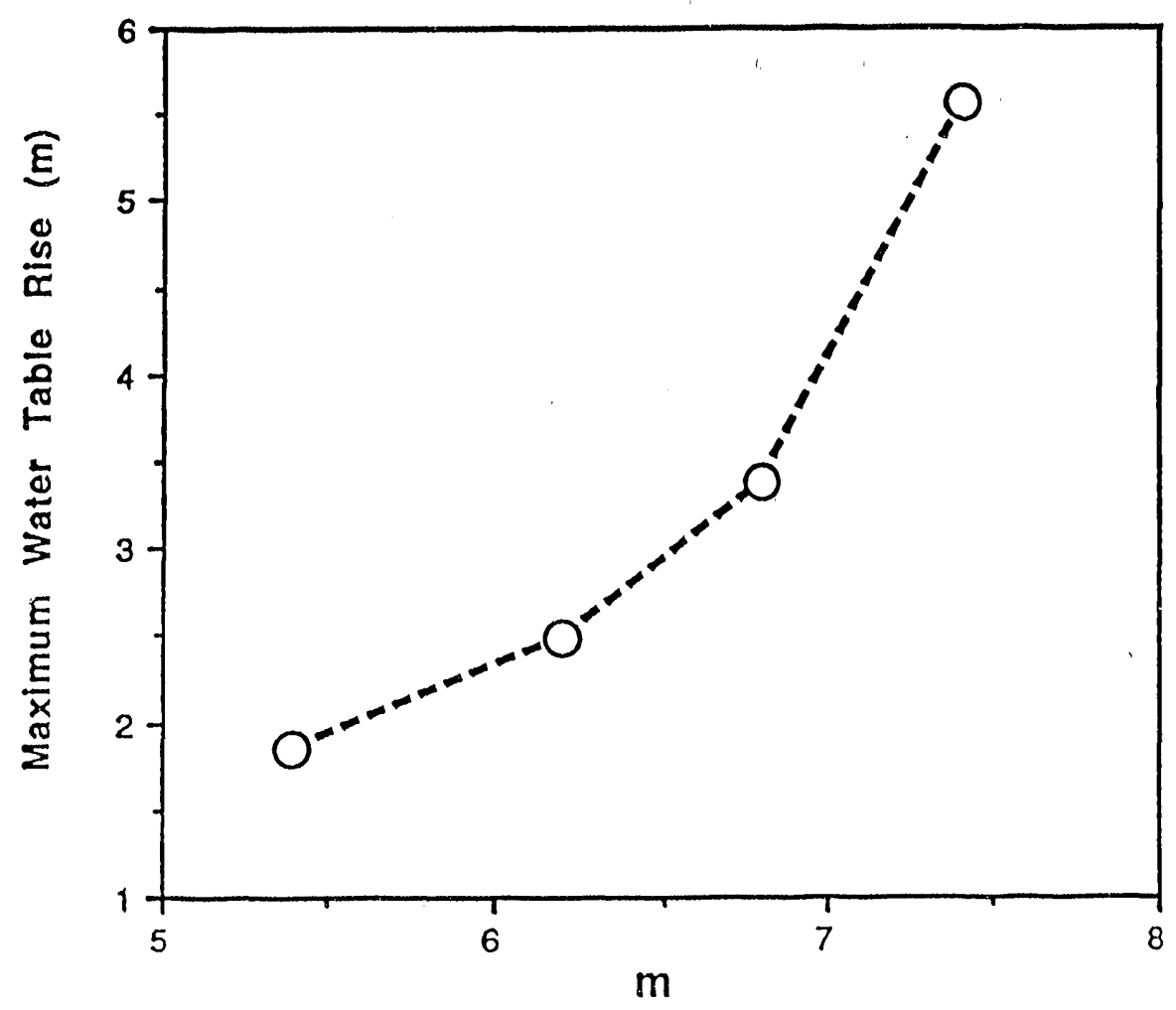




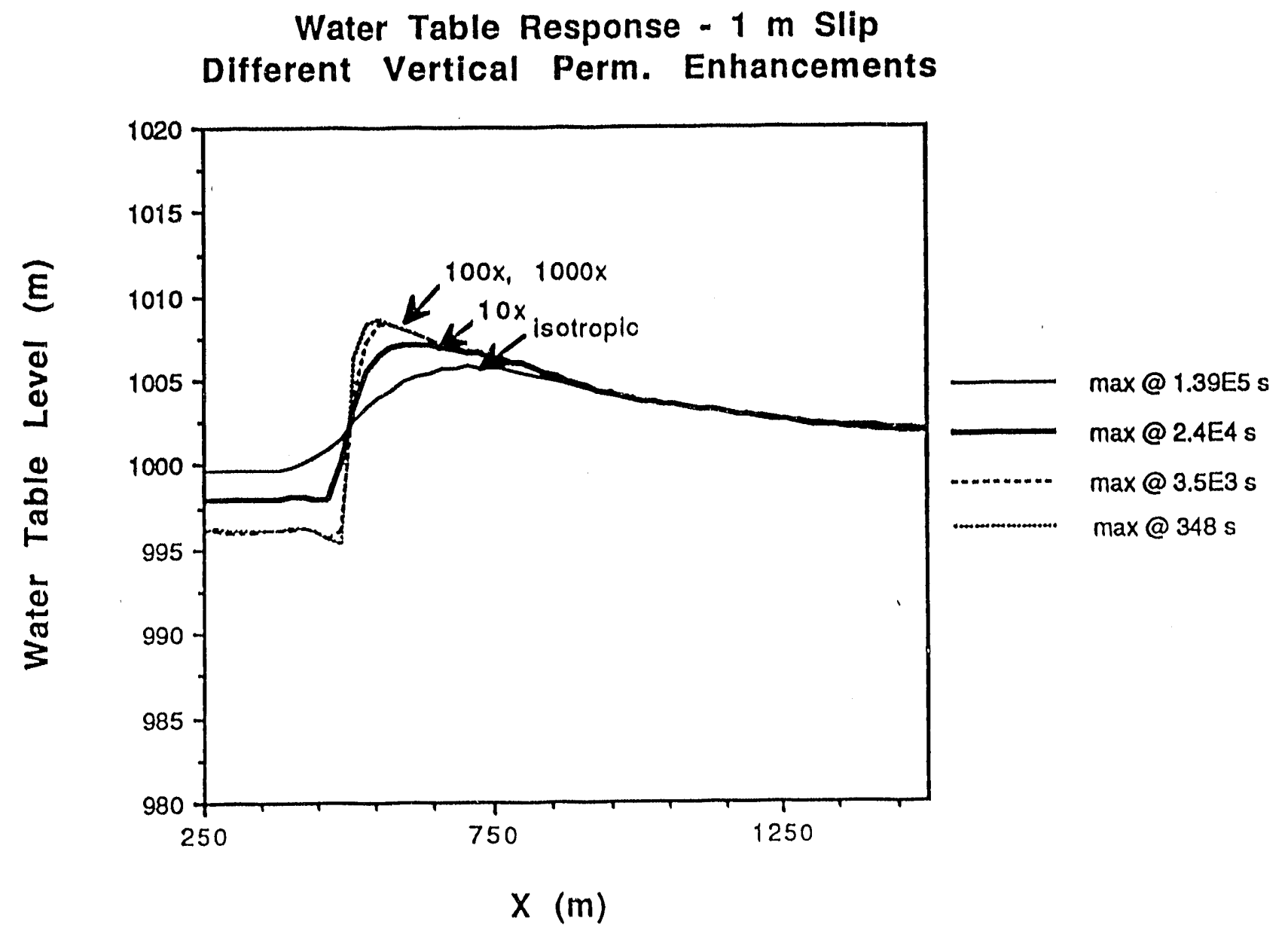


Fig. 21

\section{Water Table Response - $1 \mathrm{~m}$ Slip Local Vertical Perm Enhancements}

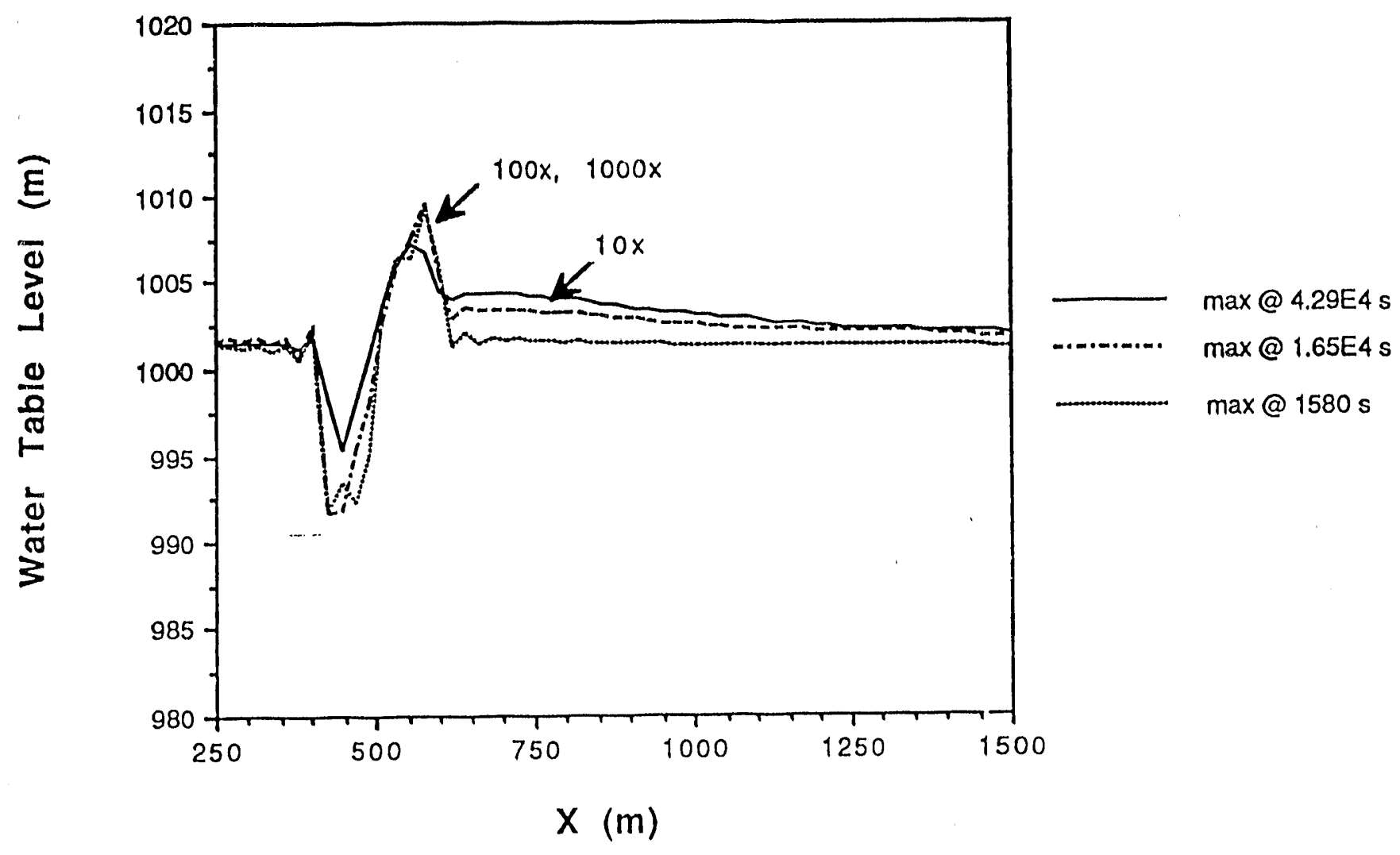


Decay of Pore Pressures > 25 Bars

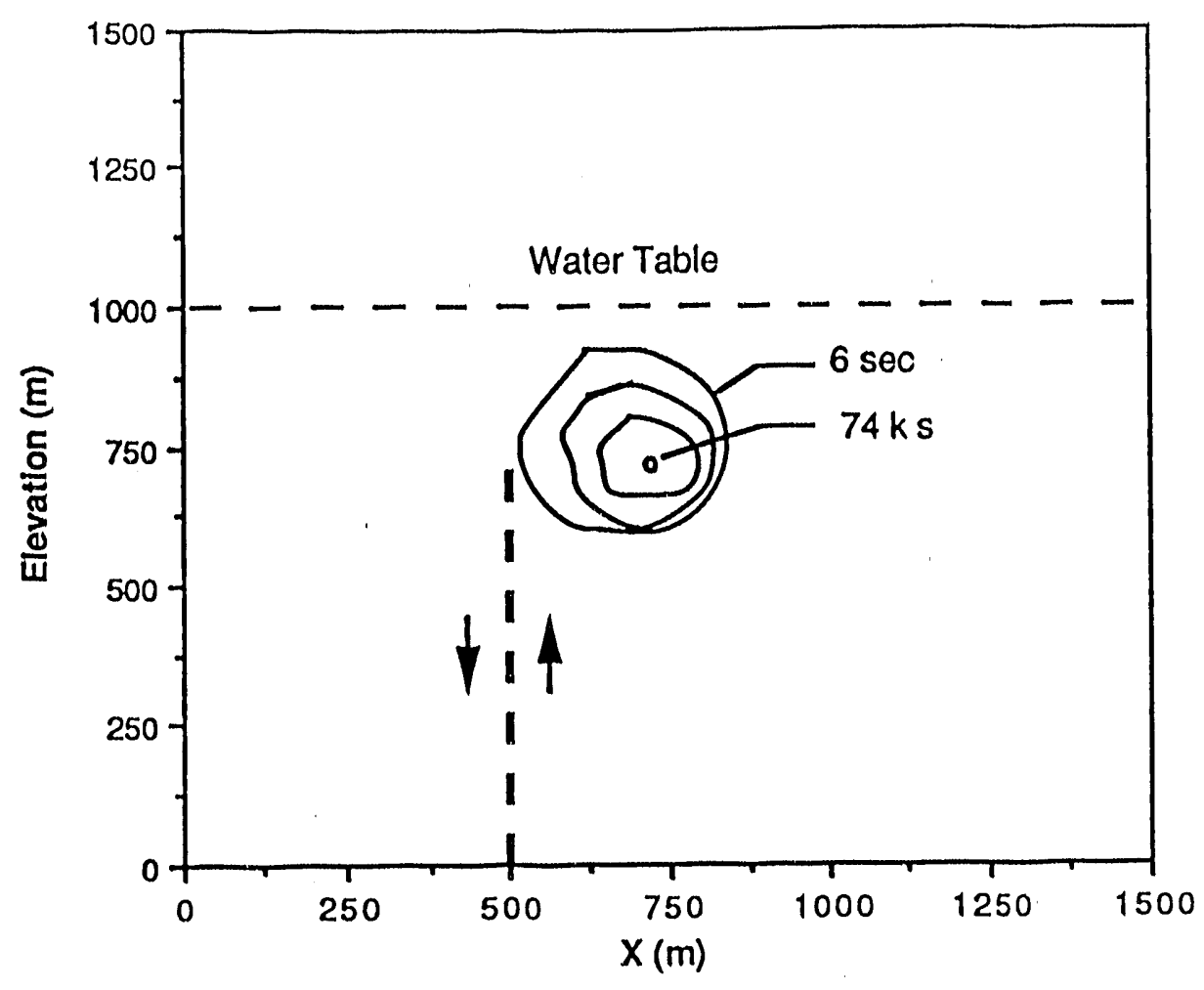




\section{Zone of Pore Pressures Capable of Supporting $250 \mathrm{~m}$ Head}

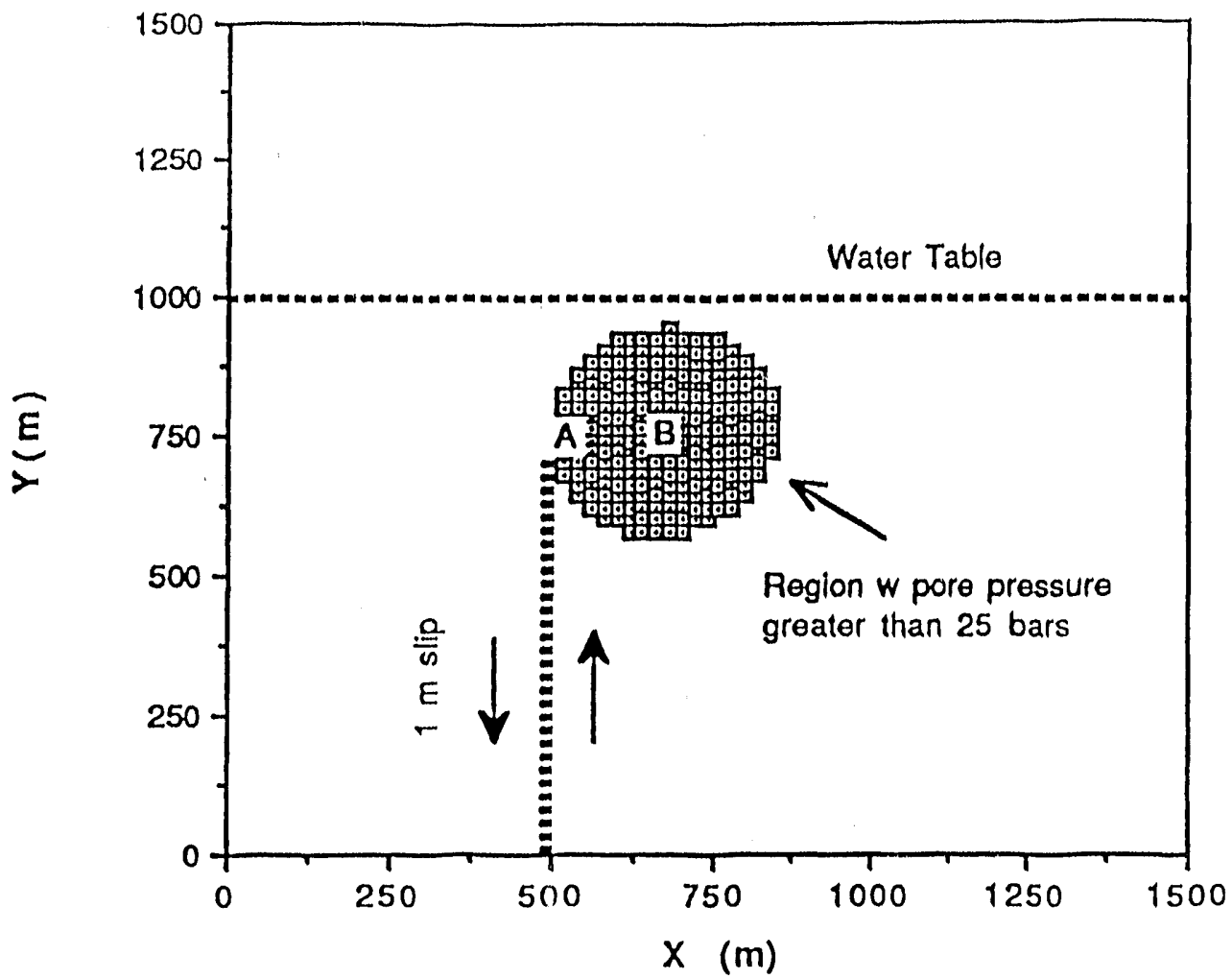

Decay of Pore Pressures at Two Locations $\mathrm{CHv}$ Properties - $1 \mathrm{~m}$ Slip

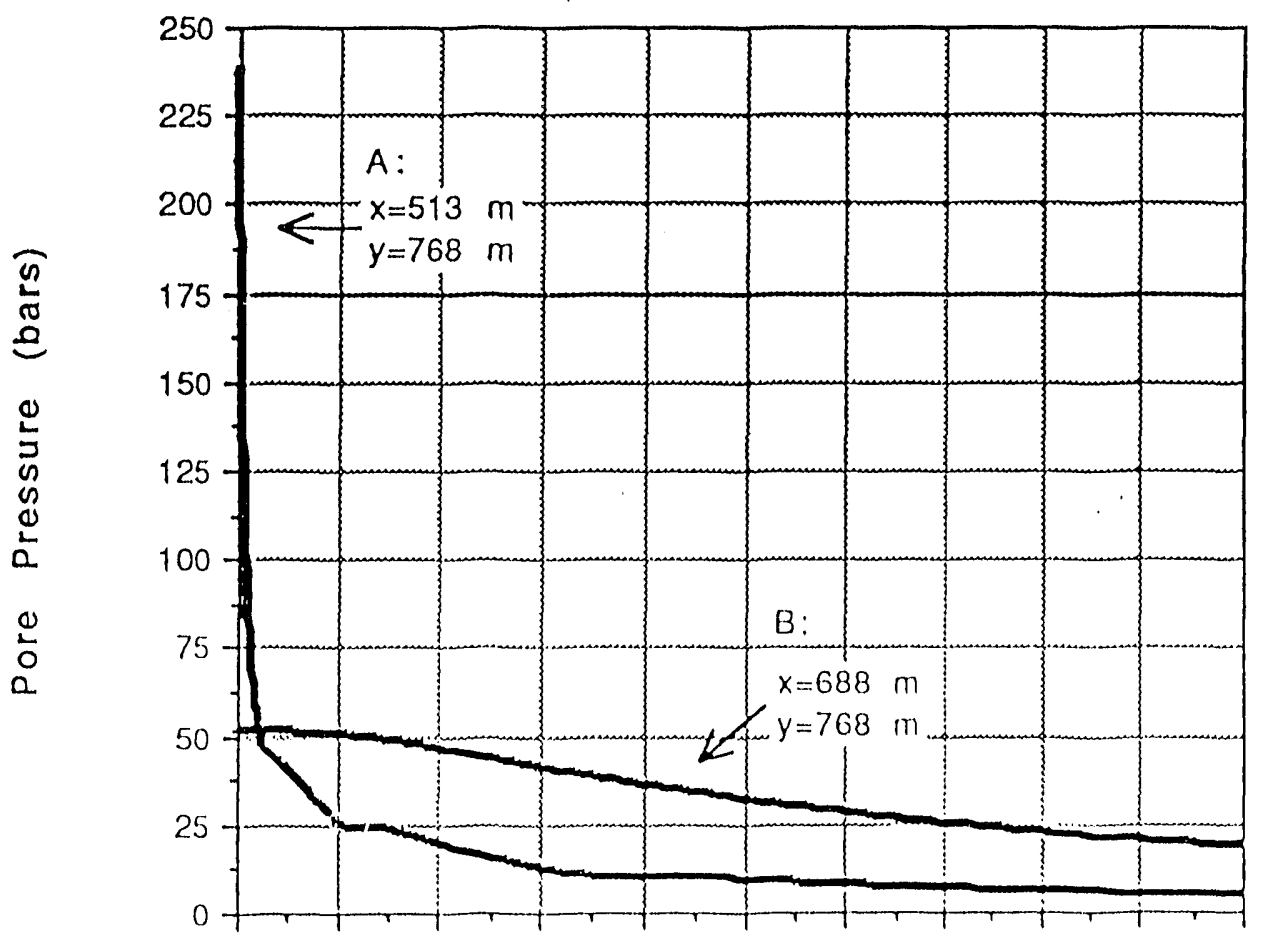

$0 e+010+420+430+440+450+46 \theta+47 e+480+490+410+! 5$

$\operatorname{lime~(s)~}$ 
Volume Produced per Unit Area at $250 \mathrm{~m}$
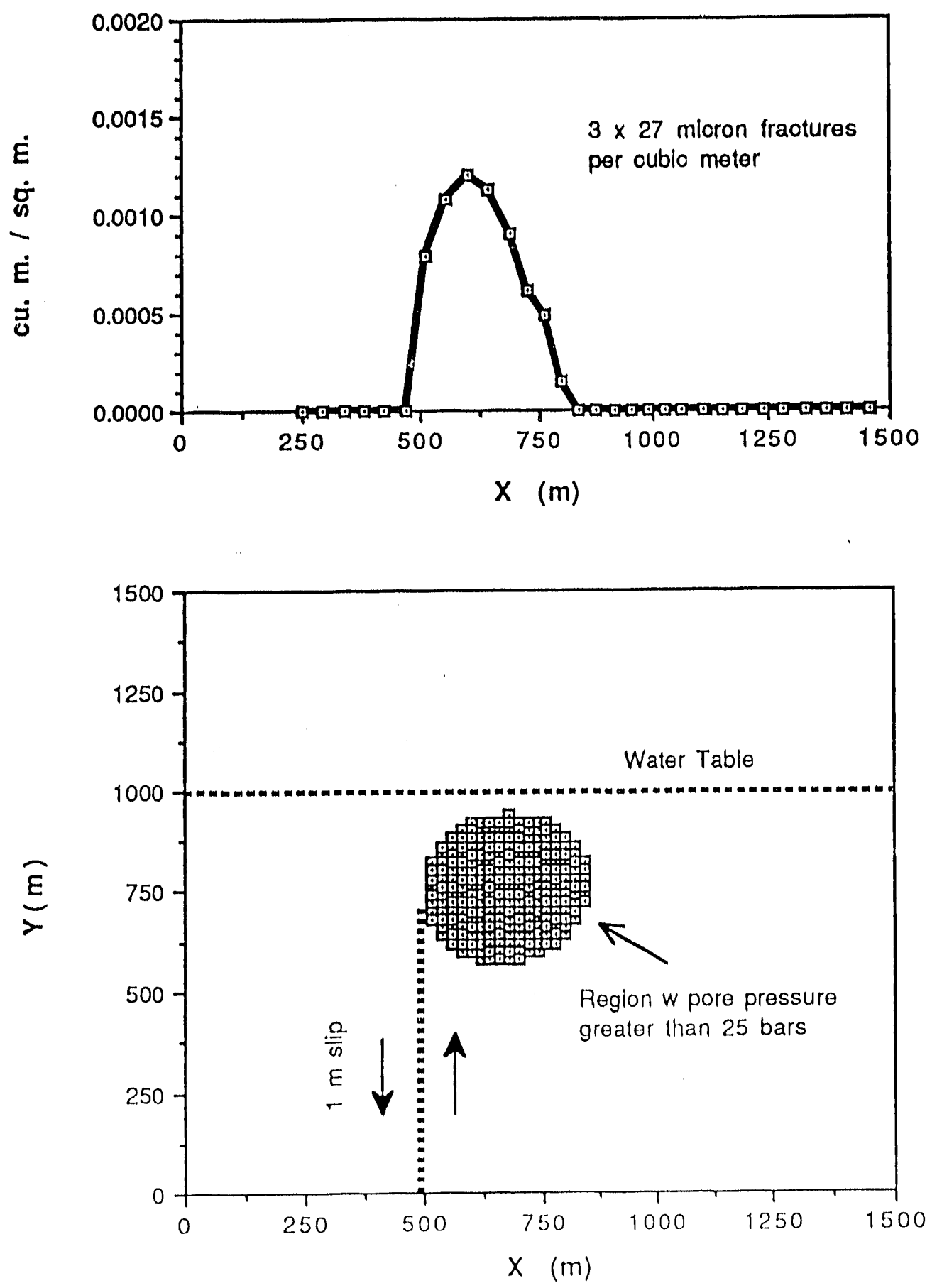
F1g. 25

Total Volume of Water Raised $250 \mathrm{~m}$

$3 \times 27$ micron Fracture System

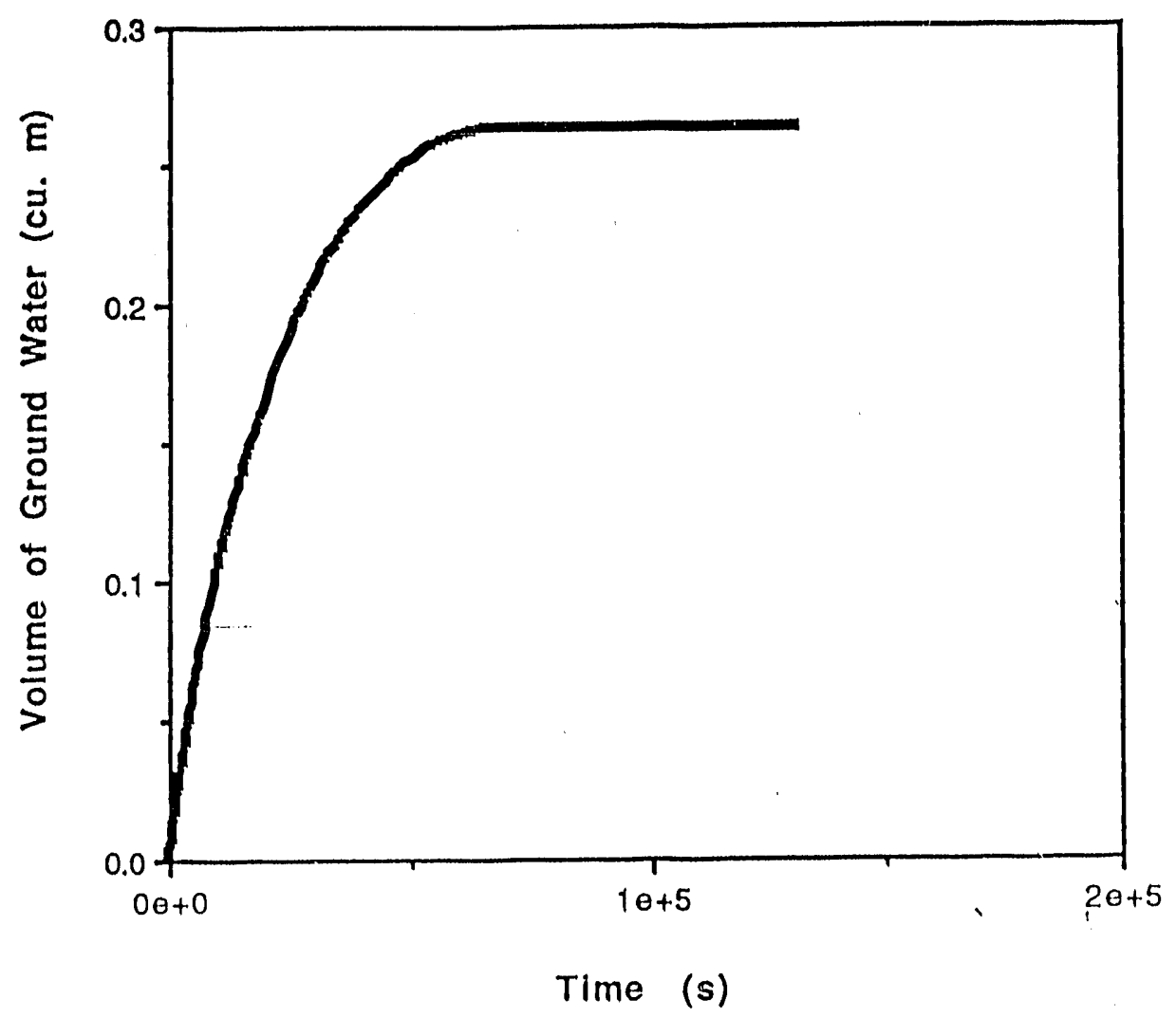


Excess Ground Water Volume

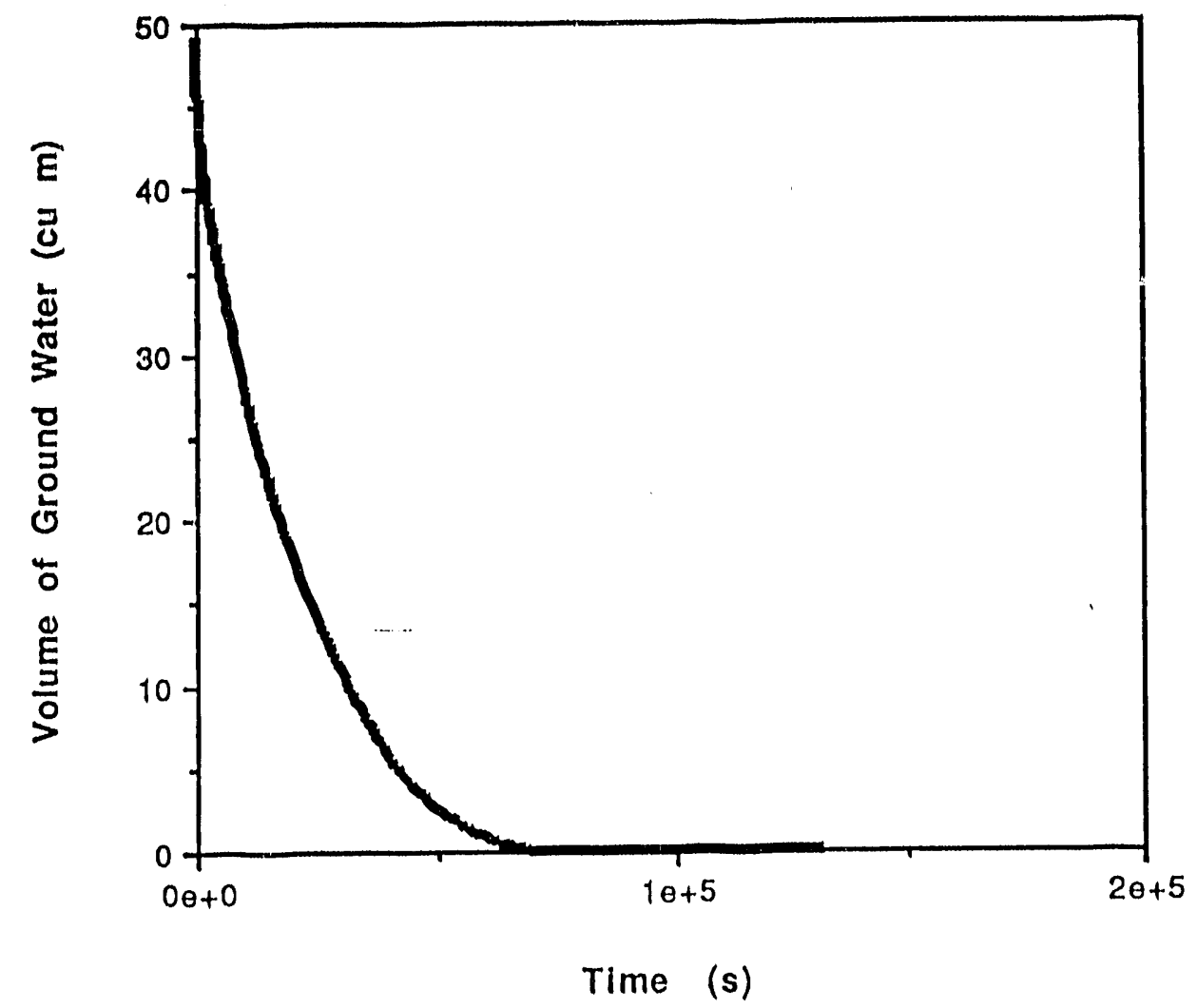




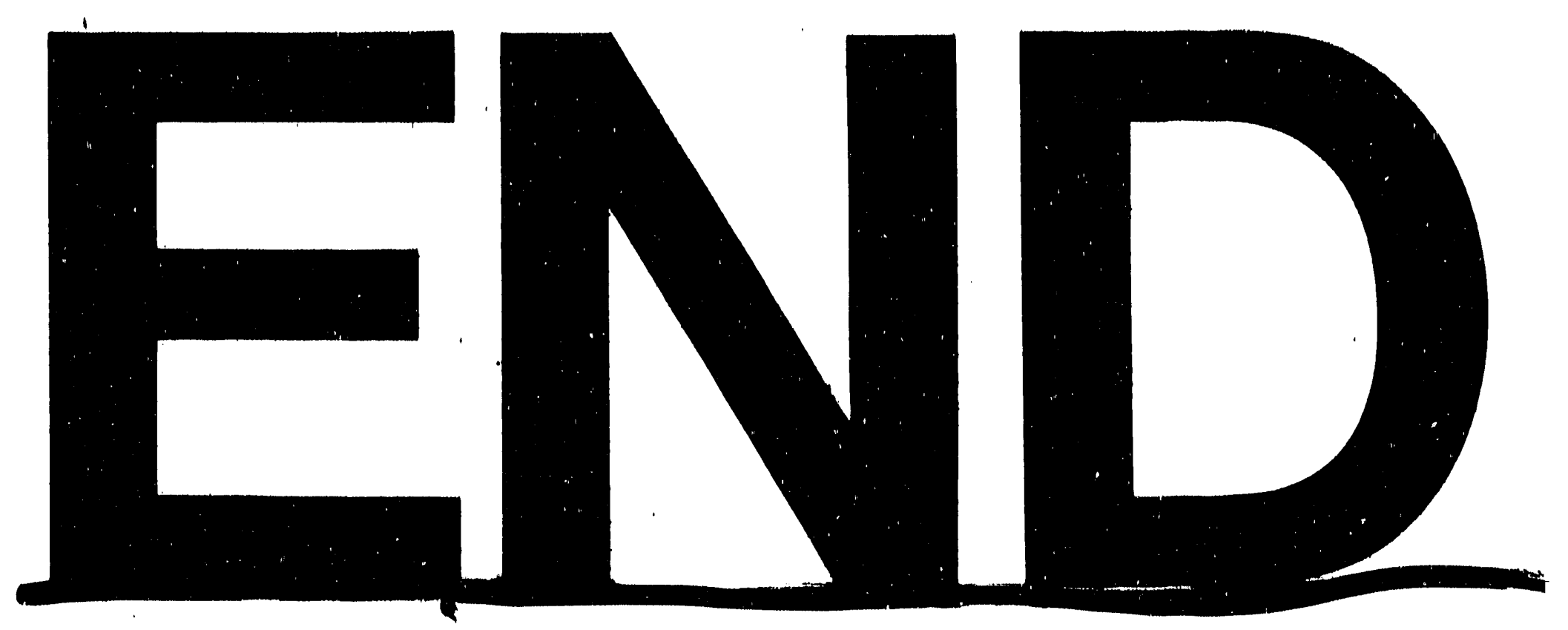

I

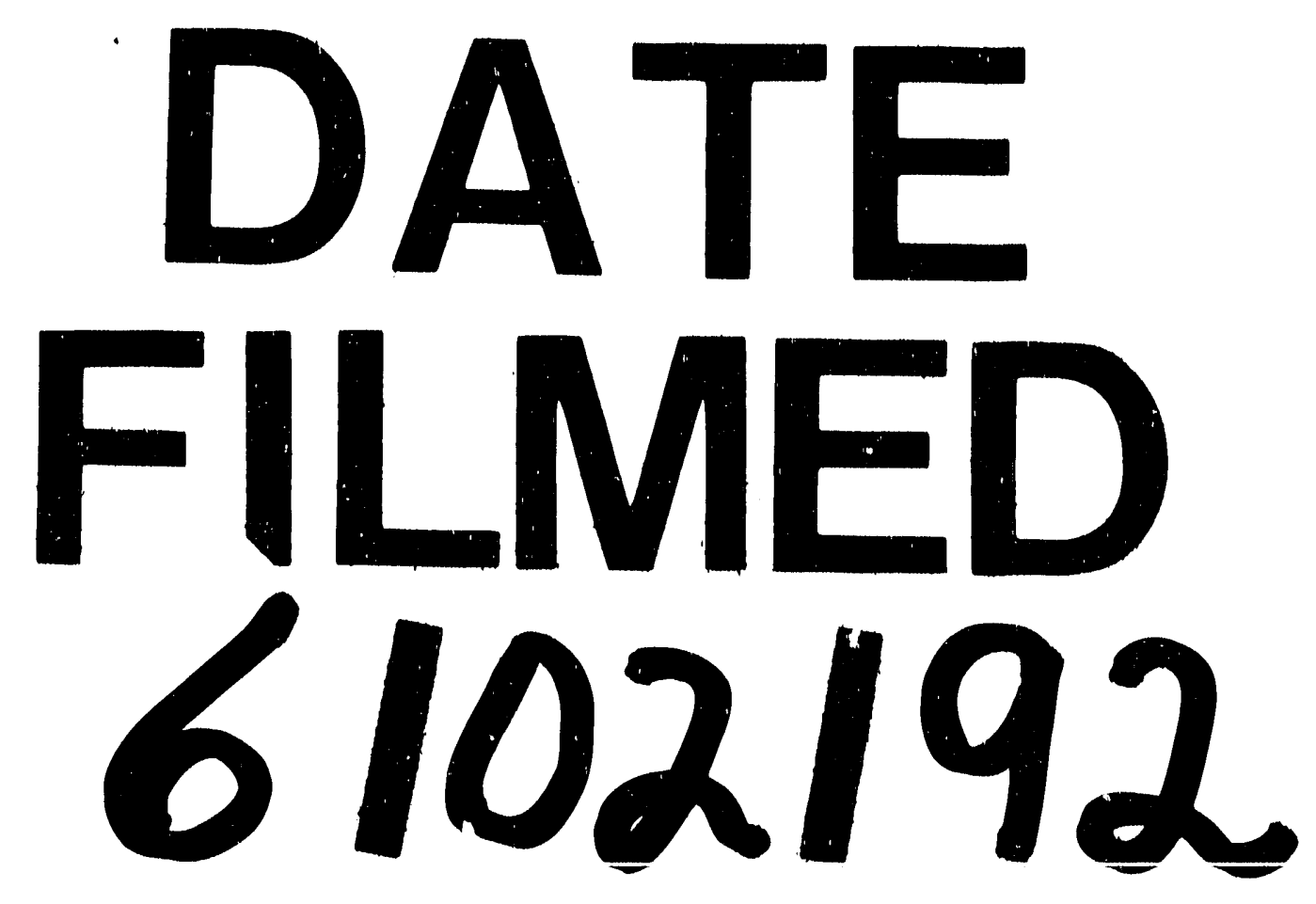


